
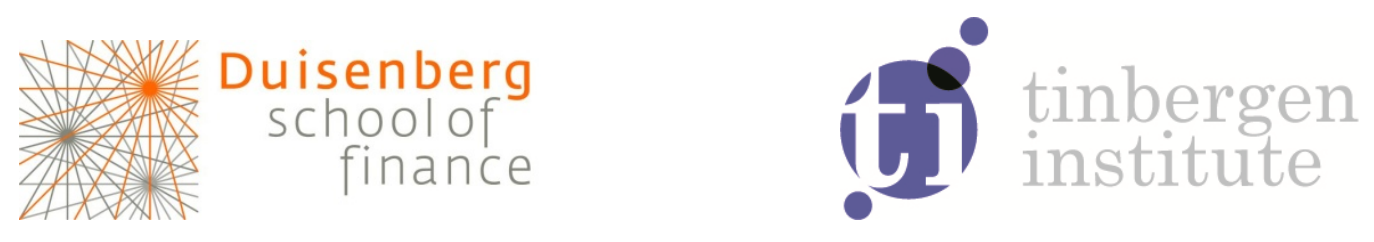

Duisenberg school of finance - Tinbergen Institute Discussion Paper

TI 13-180 /IV / DSF 66

The Size Effect in Value and Momentum Factors:

Implications for the Crosssection of International Stock Returns

Victoria Atanasov'

Thomas Nitschka

${ }^{1}$ Faculty of Economics and Business Administration, VU University Amsterdam, and Tinbergen Institute, The Netherlands;

2 Swiss National Bank, Switzerland. 
Tinbergen Institute is the graduate school and research institute in economics of Erasmus University Rotterdam, the University of Amsterdam and VU University Amsterdam.

More TI discussion papers can be downloaded at http://www.tinbergen.nl

Tinbergen Institute has two locations:

Tinbergen Institute Amsterdam

Gustav Mahlerplein 117

1082 MS Amsterdam

The Netherlands

Tel.: +31(0)205251600

Tinbergen Institute Rotterdam

Burg. Oudlaan 50

3062 PA Rotterdam

The Netherlands

Tel.: +31(0)10 4088900

Fax: $+31(0) 104089031$

Duisenberg school of finance is a collaboration of the Dutch financial sector and universities, with the ambition to support innovative research and offer top quality academic education in core areas of finance.

DSF research papers can be downloaded at: http://www.dsf.nl/

Duisenberg school of finance

Gustav Mahlerplein 117

1082 MS Amsterdam

The Netherlands

Tel.: +31(0)20 5258579 


\title{
The size effect in value and momentum factors: Implications for the cross-section of international stock returns
}

\author{
Victoria Atanasov \\ VU University Amsterdam \\ and Tinbergen Institute
}

\author{
Thomas Nitschka* \\ Swiss National Bank
}

November 5, 2013

\begin{abstract}
We document a consistent and robust relation between expected equity premia and common risk factors constructed on the basis of small stocks. Empirically, we show that (i) small-stock components of traditional value and momentum factors capture patterns in returns on regional and global portfolios of stocks; (ii) size-effect models substantially outperform benchmark models in finance; (iii) global small-stock value and momentum components are priced but regional models lead to more accurate asset evaluations; (iv) funding liquidity risk is a partial explanation of these findings.
\end{abstract}

JEL: G11; G12

Keywords: INTERNATIONAL STOCK RETURNS, SIZE, VALUE, MOMENTUM

\footnotetext{
*Email: v.atanasov@vu.nl; thomas.nitschka@snb.ch We thank Katrin Assenmacher, Enrique Salvador (discussant), an anonymous referee of the Swiss National Bank, participants at the Swiss National Bank Brown Bag Seminar, the Lecture Series in Economics at the University of Mainz, the Infiniti Conference on International Finance, and the Annual Meeting of Swiss Society for Economics and Statistics for helpful comments and suggestions. Parts of this research were conducted while Atanasov was at the University of Mainz. Hospitality of Beatrice Weder di Mauro is gratefully acknowledged. The views expressed in this paper are those of the authors and do not necessarily reflect the stance of the Swiss National Bank. Any errors and omissions are our own.
} 


\section{Introduction}

Growing evidence highlights the importance of small, i.e. low market capitalization, stocks for asset pricing. ${ }^{1}$ Chan et al. (1985) report, for example, that small stocks exhibit the greatest sensitivity to overall changes in expected risk premium. That is, when expected risk premia on all assets change, the risk premia on small stocks change the most (see also Keim and Stambaugh (1986)). Guided by these insights and finance research and practice which put micro-caps increasingly in the spotlight, we ask whether firm size of stocks underlying the two most studied common risk factors in standard asset pricing models_-"value" and "momentum"—entails significant implications for evaluations of risk-return relation in international equity markets.

We document consistent and ubiquitous relation between expected equity premia and common risk factors constructed on the basis of small stocks in global and regional portfolios in developed capital markets, in- and out-of-sample, across different test assets and time periods. This finding indicates the presence of systematic risks in international equity markets and has direct implications for asset pricing tests. Portfolio investment decisions are best performed by means of asset pricing models which feature the size effect in value and momentum factors.

We show that funding liquidity is a partial explanation of these findings. When illiquidity increases small assets with high ratios of fundamentals (like book equity) to their current market prices, termed "value", tend to offer lower returns than small assets with low respective ratios, termed "growth"; and small assets with strong recent relative

\footnotetext{
${ }^{1}$ Banz (1981), Reinganum (1981), and Fama and French (2012), among others, document the size effect; Berk et al. (1999), Gomes et al. (2003) and Zhang (2005) provide a theoretical rationalization of the size effect; Fama and French (1995), Petkova and Zhang (2005), Liew and Vassalou (2000), Kapadia (2011), De Moor and Sercu (2013a, 2013b) and many others investigate the size effect empirically.
} 
performance history, termed "winners", yield lower returns compared to small assets with weak recent performance, termed "losers". As a result, funding illiquidity is important, even though it cannot replace small-stock value and momentum pricing factors. Since liquidity is non-traded and cannot be observed directly but has to be estimated, it is not surprising that small-stock risk factors have superior explanatory power for returns.

The starting point for our analysis is the three-factor model of Fama and French (1993) and its four-factor extension of Carhart (1997). The first model relates expected returns to the excess market return, a factor mimicking an aggregate size premium (SMB, small-minus-big) — measured by the difference between the returns on small stocks and the returns on big stocks — and one related to the value effect (HML, high-minuslow)—proxied by the difference in returns on value and growth stocks. The second model introduces additionally a momentum factor (WML, winner-minus-loser)computed as the difference in returns on winners and losers. Based on their empirical validity and easy tractability, these models have become, alongside with the CAPM of Sharpe (1964) and Lintner (1965), the standard benchmark asset pricing models, and the returns on value and momentum strategies emerge as two most studied capital market phenomena in financial economics.

In this paper, we offer new insights into these two factors by examining their behaviour across small stocks and big stocks separately and show that the performance of the conventional multifactor models in finance can be substantially improved once the sizeeffect in value and momentum is taken into account. ${ }^{2}$ We find that cross-sectional

\footnotetext{
${ }^{2}$ In his unpublished manuscript, Zhang (2008) decomposes the size factor in its value and growth components to explain time variation in US stock returns.
} 
dispersion in equity returns on regional and global stocks can be rationalized by differences in assets' sensitivities to the small-stock components of the HML and WML factors: Value premium is explained by different return reagibilities to the small-stock value factor, while spreads in momentum returns are captured by their different reagibilities to the small-stock momentum factor. This is one of our central findings. Asness et al. (2013) also find that two different factors-a zero-cost value strategy and a zero-cost momentum strategy—best explain value and momentum in the data, rather than a single factor, since both strategies generate positive excess returns yet are negatively correlated.

There is both theoretical and empirical reason to expect that small-stock spreads are linked to risk premia in equity markets. Theoretical papers on production-based models ${ }^{3}$ explicitly tie the changes in firms' risk over time to firm-specific variables in such a fashion that asset turnover, costly reversibility and countercyclical price of risk make physically small stocks endogenously riskier especially in bad times. Numerous empirical studies ${ }^{4}$ propose companies’ profitability, time-variation in the investment opportunity set, trading costs, bankruptcy, financial distress, liquidity, default, macroeconomic and business cycle related risks as well as market incompleteness, information delay and investor behaviour as competing rationalizations of the size effect in the data.

This small-stock common risk structure has a consequence that size-effect models outperform the conventional benchmark models in terms of pricing errors and general

\footnotetext{
${ }^{3}$ See for example Cochrane (1996), Berk et al. (1999), Gomes et al. (2003) and Zhang (2005).

${ }^{4}$ See Liew and Vassalou (2000), Heaton and Lucas (2000), Lettau and Ludvigson (2001), Petkova and Zhang (2005), Yogo (2006), Chen et al. (2008), Kapadia (2011), and references in the surveys of Schwert (1983) and van Dijk (2011).
} 
fit. However, Lewellen and Nagel (2006) argue that this success can be an outcome of a false treatment of the slopes in the second stage Fama-MacBeth (1973) regressions as free parameters or statistically unreliable evaluation methods. We address these concerns in several ways. First, we take the theoretical guidance seriously and enforce a zero-beta restriction as recommended by Lewellen et al. (2010). We find that the economic magnitudes of risk premia associated with factor mimicking portfolios are closely related to the factors' expected excess returns as the factors are traded. Second, we follow a guideline of Kan et al. (2013) and employ the $R^{2}$ in a single crosssectional regression for average returns as a measure of "goodness-of-fit", since the average of monthly cross-sectional $R^{2}$ 's is often overoptimistic and may falsely neglect economic or statistical plausibility. Third, we report both ordinary least squares (OLS) and generalized least squares (GLS) estimations as well as the OLS and GLS cross-sectional $R^{2}$ 's. If the residuals in a cross-sectional regression are correlated with each other, standard textbook advocates the use of GLS rather than OLS (Cochrane (2005)). Kan et al. (2013) note that the former is more relevant in tests of a particular set of assets, whereas the latter-despite the apparent difficulties in its interpretationis more informative from an investment perspective. In this respect, Lewellen et al. (2010) emphasize that at least some of the doubts about the interpretation of GLS $R^{2}$ are misplaced. They show that in the framework of Fama-MacBeth (1973) regressions the GLS $R^{2}$ is determined by the proximity of the mimicking portfolios to the minimum variance boundary. Fourth, to relax the tight factor structure of returns and improve the quality of our tests we follow a further endorsement in Lewellen et al. (2010) and expand the set of test assets to portfolios formed on industry and other 
characteristics such as cash flow-price, dividend-price, and earnings-price ratios. Our experiments support the importance of small-stock value and momentum components for risk-return relation on equity markets and strongly favour size-effect models.

We then ask whether global or regional versions of the small-stock common risk factors can better explain the dispersion in international size, value, and momentum returns. In their tests of financial market integration, Fama and French (2012) focus on time-series regressions of the benchmarks. We first extend this evidence to size-effect models. In a next step, we complement the analysis in Fama and French (2012) with extensive crosssectional asset pricing tests. Similar to Griffin (2002) who argues that country-specific versions of the three-factor model are a better description of international stock returns compared to a global version of the model, Fama and French (2012) conclude that regional factors generate a better fit than global factors. Our empirical results indicate that global small-stock risk factors are significantly priced but regional models generally lead to more accurate portfolio evaluations. This result is important for practical applications such as calculations of the required rate of return and portfolio evaluations but also from an economic perspective. Our findings may signal incomplete financial integration (see e.g. Nitschka (2010)) but can also reflect model misspecification.

Further we investigate the sources of the common structure in value and momentum small-stock components. By understanding the drivers behind these factors, we can better understand their explanatory power in the data. When examining value and momentum jointly, we find that liquidity risks are a partial explanation of our findings. Small-stock value (past winner) stock returns drop when funding liquidity collapses, 
and this can explain why value (past winners) stocks on average outperform growth (past losers) stocks. A link to measures of investor sentiment and near-term market volatility can explain why small-stock value and momentum strategies fail to payoff in months of high volatility and low funding liquidity. These findings are closely related to Asness et al. (2013) who show that value and momentum return premia across diverse markets and asset classes are related to global funding liquidity risk, which is identifiable only when value and momentum are examined jointly. Other relevant papers include Kapadia (2011) who highlights the importance of aggregate distress risk for small stocks, and Lustig et al. (2011) and Menkhoff et al. (2012) who suggest that global market volatility and liquidity are important for understanding of currency excess returns. In terms of economic magnitudes, funding liquidity can account for a fraction of patterns in financial market data and thus provides a partial and incomplete rationalization of our findings.

From a technical point of view, our work echoes several studies which document that value and momentum are strongly related to factors associated with size (e.g., Reinganum (1981) and Fama and French (2012)). From an economic point of view, our results provide further support for the idea that assets' exposures to systematic risk sources are responsible for differences in expected returns across assets-the key insight in financial economics.

The remainder is organized is follows. Section 2 presents the methodology and motivates the modified multifactor size-effect models. Section 3 describes the data set of regional and global stock portfolios. Section 4 discusses our main empirical results 
and their robustness. Section 5 links risks in small-stock factor components to funding liquidity, and Section 6 concludes.

\section{Theoretical and empirical framework}

In this section, we briefly present the methodology we employ in our empirical analysis. We then describe the standard asset pricing models for stock returns that are commonly used as benchmarks in the finance literature. Subsequently, we introduce and motivate our preferred alternatives.

\subsection{General methodology}

Our asset pricing tests rely on a two-stage regression methodology of Fama and MacBeth (1973) which emerges as one of the most popular approaches for estimating and testing linear asset pricing models. The first stage runs an unconditional time-series regression to obtain the estimates of factor loadings $\beta_{i}$ :

$$
R_{i}^{e}=\alpha_{i}+\beta_{i}^{\prime} F+\varepsilon_{i}
$$

where $R_{i}^{e}$ is the excess return on asset $i(i=1, \ldots, N), F$ is a $(K x 1)$ vector of pricing factors or factor portfolio returns in the case of traded factors, $\alpha_{i}$ is a constant, and $\varepsilon_{i}$ is an idiosyncratic error term. ${ }^{5}$

In the second stage, the factor risk premia $\lambda$ are estimated from a cross-sectional regression of average excess returns on the betas

$$
E\left(R_{i}^{e}\right)=\lambda^{\prime} \beta_{i}+e_{i},
$$

where $E$ denotes the expectation operator and the residuals $e_{i}$ are conventionally interpreted as the pricing errors. Relation (2) states that the expected excess return on a risky asset $i$ is linear in its betas. ${ }^{6}$

\footnotetext{
${ }^{5}$ Here and later we skip the time indices for simplicity of notation.
} 
Several points are worth mentioning as regards the empirical implementation of and statistical inference in the cross-sectional asset pricing tests. First, Lewellen et al. (2010) emphasize the importance of imposing theoretical restrictions ex ante and caution against a false treatment of the slopes in the second stage Fama-MacBeth (1973) regressions as free parameters. We address this concern by taking the theoretical guidance seriously and enforcing a zero-beta restriction, i.e. we do not include a constant in the second-stage equation as we are working with excess returns.

Second, in the original Fama and MacBeth (1973) study, the betas in the cross-sectional regression (2) are estimated using rolling-window regressions from past data, and the lambdas and the $R^{2}$ in (2) are estimated as averages of the slopes and the $R^{2}$ s from a series of cross-sectional regressions, respectively. Kan and Robotti (2012) note, however, that computing the average risk premia and the $R^{2}$ from a time-series estimates of $\lambda$ 's and $R^{2}$ 's, respectively, is dangerous, as this procedure may neglect the economic and statistical significance. Against this backdrop, we follow a recommendation of Kan et al. (2013) and run a single cross-sectional regression of average excess returns on the full sample beta estimates in our benchmark specification and employ the $R^{2}$ in a single cross-sectional regression for average returns as a measure of "goodness-of-fit". We test the sensitivity of these results to time-variation in betas and lambdas.

Third, as the regression residuals in (2) are correlated with each other, the standard textbook recommendation is to run a GLS cross-sectional regression instead of OLS

\footnotetext{
${ }^{6}$ The beta representation follows from the basic pricing equation for excess returns $0=E\left(m R_{i}^{e}\right)$ with a linear stochastic discount factor $m=a+b^{\prime} F$, where $a$ denotes a constant and $b$ a $(K \times 1)$ vector of unknown parameters.
} 
(Cochrane (2005)). However, as the weighting matrix may be generally hard to estimate or invert, efficiency gains of GLS over OLS are associated with robustness losses. Hence, for our asset pricing tests, we report both OLS and GLS estimates. Related to this point, Kan et al. (2013) note that the OLS is more relevant in tests of a particular set of assets, whereas the GLS-despite the apparent difficulties in its interpretation-is more informative from an investment perspective. In this vein, Lewellen et al. (2010) argue that the cross-sectional OLS $R^{2}$ is in many cases overoptimistic, while the GLS $R^{2}$ is generally more reliable as a measure of goodnessof-fit of the model. They point out that the estimates of risk premia in (2) are the same regardless of whether the variance-covariance matrix of portfolio returns or the variance-covariance matrix of time-series residuals from (1) is employed as the weighting matrix in the cross-sectional GLS. For the purpose of model comparison, it makes, however, sense not to use weighting matrices that are model dependent, as these test statistics cannot be employed to perform model comparison (Kan and Robotti (2012)). To this end, we use a "normalized" goodness-of-fit measure with the same weighting matrix across models, i.e. the variance-covariance matrix of returns, and report both the adjusted OLS $R^{2}$ and the GLS $R^{2}$ in (2). Following Kandel and Stambaugh (1995), the latter is defined ${ }^{7}$ as $\rho_{G L S}^{2}=1-\frac{e_{w}^{\prime} W e_{w}}{e_{0}^{\prime} W e_{0}}$, where $e_{W}$ is the pricing error in the GLS cross-sectional regression and $e_{0}$ represents the weighted deviations of mean returns from their cross-sectional average.

\footnotetext{
${ }^{7}$ Similar to the OLS case, the goodness-of-fit measure in GLS regressions without a constant term is not bounded.
} 
Finally, as the betas in the second-stage regression are measured with error, the risk prices in (2) are subject to the errors-in-variables (EIV) bias. To correct the standard errors, we follow Shanken (1992).

\subsection{Standard benchmark pricing models}

This section briefly presents three standard workhorse models in finance commonly used as the benchmarks. The first is the capital asset pricing model (CAPM) of Sharpe (1964) and Lintner (1965) which identifies sensitivity to the return on the market portfolio as the only common factor which determines expected returns. In this special case, the general representation in (2) reduces to

$$
E\left(R_{i}^{e}\right)=\lambda_{M} \beta_{M}^{i}+e_{i}
$$

where $\beta_{M}^{i}$ is the sensitivity of asset $i$ to fluctuations in the market portfolio excess return and $\lambda_{M}$ is the market risk premium.

The second benchmark is the three-factor model of Fama and French (1993) which argues that portfolios constructed to mimic risk factors related to size-proxied by market equity (ME) — and value-proxied by the ratio of book-to-market equity (BE/ME) — should substantially add to the explanatory ability of the CAPM market beta:

$$
E\left(R_{i}^{e}\right)=\lambda_{M} \beta_{M}^{i}+\lambda_{S M B} \beta_{S M B}^{i}+\lambda_{H M L} \beta_{H M L}^{i}+e_{i} .
$$

The factors in this model are constructed using six value-weight portfolios formed independently on size and BE/ME:

\begin{tabular}{cccc}
\hline \hline & $\begin{array}{c}\text { Low BE/ME } \\
\text { (Growth) }\end{array}$ & $\begin{array}{c}\text { Medium BE/ME } \\
\text { (Neutral) }\end{array}$ & $\begin{array}{c}\text { High BE/ME } \\
\text { (Value) }\end{array}$ \\
\hline Low ME (Small) & SG & SN & SV \\
High ME (Big) & BG & BN & BV \\
\hline \hline
\end{tabular}


In Equation (4), $\beta_{S M B}^{i}$ is the sensitivity of asset $i$ to the return on a factor mimicking portfolio SMB (small-minus-big) measured as the equal-weight average of the returns on the three small stocks from the 2x3 size-BE/ME sorts minus the average of the returns on the three big stocks, i.e. $\mathrm{SMB}=1 / 3 *(\mathrm{SG}+\mathrm{SN}+\mathrm{SV})-1 / 3 *(\mathrm{BG}+\mathrm{BN}+\mathrm{BV})$. Analogously, $\beta_{H M L}^{i}$ is the sensitivity of asset $i$ to the return on a factor mimicking portfolio HML (high-minus-low) measured as the equal-weight average of the returns for the two high $\mathrm{BE} / \mathrm{ME}$ portfolios minus the average of the returns for the two low BE/ME portfolios, i.e. HML = 1/2*(SV+BV)- $1 / 2 *(S G+B G)$.

The third benchmark is the four-factor Carhart (1997) model which enhances the threefactor model with an additional factor related to the Jegadeesh and Titman's (1993) continuation of short-term returns (momentum):

$$
E\left(R_{i}^{e}\right)=\lambda_{M} \beta_{M}^{i}+\lambda_{S M B} \beta_{S M B}^{i}+\lambda_{H M L} \beta_{H M L}^{i}+\lambda_{W M L} \beta_{W M L}^{i}+e_{i},
$$

where the momentum factor WML (winners-minus-losers) is constructed as the equalweight average of the returns for the two winner portfolios minus the equal weight average of the returns for the two loser portfolios from six size- and momentum sorted portfolios, i.e. $\mathrm{WML}=1 / 2 *(\mathrm{SW}+\mathrm{BW})-1 / 2 *(\mathrm{SL}+\mathrm{BL})$ :

\begin{tabular}{cccc}
\hline \hline & $\begin{array}{c}\text { Low past returns } \\
(\text { Loser })\end{array}$ & $\begin{array}{c}\text { Medium past returns } \\
(\text { Neutral) }\end{array}$ & $\begin{array}{c}\text { High past returns } \\
\text { (Winner) }\end{array}$ \\
\hline Low ME (Small) & SL & SN & SW \\
High ME (Big) & BL & BN & BW \\
\hline \hline
\end{tabular}

\subsection{Three alternative empirical models}

The motivation for empirical asset pricing models usually comes from observed patterns in returns; that is, models fit the data without specifying the economic 
fundamental processes behind asset price changes. In this respect, our work emerges as a natural response to recent evidence suggesting that value premium and spreads in average momentum returns are strongest among micro-caps (Jegadeesh and Titman (1993), Hong et al. (2000), Petkova and Zhang (2005), Fama and French (2012)). This argument is underscored by De Moor and Sercu (2013b) who emphasize the importance of an additional micro-stock risk factor in standard asset pricing models.

In economic terms, there is reason to expect that small-stock components of value and momentum factors capture common risks in stock returns. Both theoretical and empirical studies indicate that the size effect reflects macroeconomic business cycle related, aggregate financial distress and liquidity risks. ${ }^{8}$

To investigate the cross-sectional implications of the size effect in value and momentum we distinguish between (i) small-stock value factor (HMLS) and big-stock value factor (HMLB) in the three-factor Fama and French (1993) model and (ii) smallstock momentum factor (WMLS) and big-stock momentum factor (WMLB) in the fourfactor Carhart (1997) model. We evaluate a modified version of the three-factor FamaFrench model which splits HML into a small-stock component-measured as a difference between returns on small value and small growth stocks (HMLS = SVSG)—and a big-stock component—-measured as a difference between big value and big growth stocks (HMLB = BV-BG):

$$
E\left(R_{i}^{e}\right)=\lambda_{M} \beta_{M}^{i}+\lambda_{S M B} \beta_{S M B}^{i}+\lambda_{H M L S} \beta_{H M L S}^{i}+\lambda_{\text {HMLB }} \beta_{H M L B}^{i}+e_{i} .
$$

Analogously, we assess the asset pricing implications of the size effect in momentum in a framework of a modified version of the four-factor Carhart model which decomposes

\footnotetext{
${ }^{8}$ We summarize main references in the introduction.
} 
WML into a small-stock component-measured as a difference between returns on small winner and small loser stocks (WMLS = SW-SL)—and a big-stock component— measured as a difference between big winner and big loser stocks (WMLB = BW-BL):

$$
E\left(R_{i}^{e}\right)=\lambda_{M} \beta_{M}^{i}+\lambda_{S M B} \beta_{S M B}^{i}+\lambda_{H M L} \beta_{H M L}^{i}+\lambda_{W M L S} \beta_{W M L S}^{i}+\lambda_{W M L B} \beta_{W M L B}^{i}+e_{i}
$$

Finally, a combination of the HML and WML decompositions underlying Equations (6) and (7) above results in a six-factor model

$$
E\left(R_{i}^{e}\right)=\lambda_{M} \beta_{M}^{i}+\lambda_{S M B} \beta_{S M B}^{i}+\lambda_{H M L S} \beta_{H M L S}^{i}+\lambda_{H M L B} \beta_{H M L B}^{i}+\lambda_{W M L S} \beta_{W M L S}^{i}+\lambda_{W M L B} \beta_{W M L B}^{i}+e_{i}
$$

which allows a joint examination of the size effect in value and momentum. This specification is motivated by the ambition to have a single model that explains returns across different asset classes and Asness et al. (2013) who show that the identification of fundamentals of value and momentum stocks works best when both investment strategies are considered jointly.

\section{Data}

Our analysis is based on a new international dataset introduced in Fama and French (2012) and freely available on the website of Kenneth R. French. This section first summarizes the explanatory returns related to size, value, and momentum and used as factors in our asset pricing tests. We then turn to test assets in our empirical analysis, i.e. the $5 \times 5$ stock portfolios formed on size and book-to-market equity and the $5 \times 5$ stock portfolios formed on size and momentum. The sample period covers November 1990 to July 2013.

\subsection{Common risk factors in international equity markets}

The factors are constructed from sorts of stocks into (i) two size (ME) and three value (BE/ME) groups and (ii) two size and three momentum, i.e. past monthly cumulative 
returns for $t-11$ to $t-1$, groups. The independent $2 \times 3$ sort on size and $\mathrm{BE} / \mathrm{ME}$ generates six portfolios: small growth (SG), small neutral (SN), small value (SV), big growth (BG), big neutral (BN), and big value (BV). Analogously, the second sort produces six portfolios on size and momentum: small losers (SL), small neutrals (SN), small winners (SW), big losers $(\mathrm{BL})$, big neutrals $(\mathrm{BN})$, and big winners $(\mathrm{BW})$. The sorting is done for each region as well as globally, i.e. taking into account all stocks across all regions. Small stocks are in the bottom $10 \%$ of market capitalization of stocks whereas big stocks are in the top $10 \%$ of the market capitalization. Growth stocks are in the bottom $30 \%$ of the book-to-market equity ratio sort; neutral stocks are in the middle $40 \%$; and value stocks are in the top $30 \%$ of book-to-market equity ratios.

The factors are the standard market excess return (Mkt), size (SMB), value (HML), momentum (WML), small-stock value (HMLS), big-stock value (HMLB), small-stock momentum (WMLS) and big-stock momentum (WMLB).

Average market excess returns-measured as the difference between value-weight market return and the U.S. Treasury bill—vary from negative $-0.04 \%$ in Japan to $0.80 \%$ in Asia Pacific in monthly terms. Global equity premium is on average about $0.47 \%$ with a minimum of $-19.46 \%$ in October 2008 and a maximum of $11.42 \%$ in April 2009 . Echoing Horowitz et al. (2000), we find no size premium in international returns over 1990-2013. The SMB factor switches signs and is statistically insignificant in global as well as regional returns. The value premium (HML) is positive, statistically significant (except for North America), and economically closely related across all regions. The value premium is higher for small stocks, while it turns insignificant for big stocks. Except for Japan, we observe a similar pattern with respect to momentum (WML) and 
its small-stock and big-stock components. Finally, momentum is negatively related to value in line with Asness (1997). Table 1 shows means, standard deviations, and correlation coefficients for global common risk factors. Summary statistics of regional factors are available in the online appendix.

\section{[Insert Table 1 here]}

\subsection{International size, value, and momentum sorted portfolios}

We use the factors presented in the previous subsection to study monthly value-weight dollar excess returns on 25 (5x5) international portfolios formed on (i) size (ME) and book-to-market equity (BE/ME) and (ii) size and momentum in global stock market and the four major regions around the world: North America, Europe, Japan, and Asia Pacific excluding Japan. The North American portfolios include Canada and the United States. The European portfolios include Austria, Belgium, Denmark, Finland, France, Germany, Greece, Ireland, Italy, the Netherlands, Norway, Portugal, Spain, Sweden, Switzerland, and the United Kingdom. The Japanese portfolios include only Japan. The Asia Pacific portfolios include Australia, Hong Kong, New Zealand, and Singapore. Finally, the global portfolios include all 23 countries in the four regions.

Table 2 gives average monthly returns and standard deviations for global size-BE/ME and size-momentum sorted portfolios. ${ }^{9}$ The portfolios are organized in a squared matrix with growth stocks at the left, value stocks at the right, small stocks at the top, and large stocks at the bottom. Columns V-G and W-L give the differences in extreme value and extreme growth, and extreme winner and extreme loser stocks in each size category. Column S-B gives the difference in portfolios with lowest and highest ME in each $\mathrm{BE} / \mathrm{ME}$, respectively, momentum category.

\footnotetext{
${ }^{9}$ We refer the reader to our online appendix for a summary of regional double-sorted portfolios.
} 


\section{[Insert Table 2 here]}

Value premia and the spreads in average momentum decrease, except for Japan, with size (Fama and French (2012)). Excluding Japan, average momentum premia exceed average value premia for all size groups. The size effect is economically less important, in general, and absent in Europe, except for the highest BE/ME, respectively, extreme winner stocks. Apart from Japan, there is a reverse size effect in growth stocks: Small stocks with low BE/ME ratios have lower average returns than their big counterparts. A similar pattern is revealed by extreme loser stocks in Europe and Asia Pacific. Finally, the size premium is greater for momentum than for value stocks within each percentile of both sorting variables.

\section{Empirical results}

In what follows we evaluate the models presented above on international portfolio returns in global equity markets and in four regions-North America, Europe, Japan, and Asia-Pacific-both in time-series and cross-sectional asset pricing tests. We find that the models are generally rejected. However, time-series tests for the joint hypothesis that all pricing errors are zero (Gibbons, Ross, and Shanken (1989)) consistently favour modified models with size effect in common risk factors. In terms of cross-sectional analysis, our findings point towards the small-stock components of value and momentum factors as the driving force to explain differences in returns across assets. Both in OLS and GLS tests, our modified models outperform the original benchmark models in terms of general fit and average pricing errors. Finally, our tests of international stock market integration echo previous studies which document superior performance of regional models but reveal sources of common variation across 
regions at a global level. Hence, global models should not be neglected as a tool to analyze asset prices.

\subsection{Time-series asset pricing tests with global portfolios}

We begin by examining the global portfolios formed on size, value, and momentum. The results turn out representative for regional stock markets. We briefly summarize the latter in Section 4.3, while our online appendix gives full estimates.

Table 3 summarizes time-series regressions to explain excess returns on global portfolios. The upper panel uses 25 portfolios from the $5 \times 5$ sorts on size and BE/ME; the middle panel uses 25 portfolios from the $5 \times 5$ sorts on size and momentum; the bottom panel uses a combination of the 50 portfolios. The tested models include three benchmark models described above-(A) CAPM, (B) three-factor Fama-French, (C) four-factor Carhart models-and our preferred alternatives. In the case of value portfolios, the alternative model is (D) the modified Fama-French model with value factor split into its small-stock and big-stock components. In the case of momentum portfolios, the alternative model is (D) the modified Carhart model with momentum factor split into its small-stock and big-stock components. For value and momentum portfolios jointly, the alternative model is (D) the modified Fama-French/Carhart model with value and momentum factors split into their small-stock and big-stock varieties.

\section{[Insert Table 3 here]}

The summary statistics in Table 3 include the F-test of Gibbons, Ross, and Shanken (1989) which is commonly applied to test the null that all alphas—-the pricing errors in the first-pass time-series regression—are jointly zero:

$$
\frac{T-N-K}{N}\left(1+E(F)^{\prime} \hat{\Sigma}_{f}^{-1} E(F)\right)^{-1} \hat{\alpha} \hat{\Sigma}_{\varepsilon}^{-1} \hat{\alpha} \sim F_{N, T-N-K},
$$


where $E(F)$ is the sample mean of the pricing factors, $\hat{\Sigma}_{f}$ and $\hat{\Sigma}_{\varepsilon}$ are the covariance matrices of factors and residuals, respectively, and $\hat{\alpha}$ is a vector of intercepts or pricing errors in regression (1).

Next to the GRS test we also report the average absolute value of the 25 or 50 regression intercepts for each model, their average standard errors, the average adjusted $\bar{R}_{O L S}^{2}$ as well as the term $\operatorname{SR}(\hat{\alpha})=\left(\hat{\alpha} \hat{\Sigma}_{\varepsilon}{ }^{-1} \hat{\alpha}\right)^{1 / 2}$ which is often referred to as the unexplained Sharpe ratio (SR). Gibbons et al. (1989) show that the quadratic form $\hat{\alpha} \hat{\Sigma}_{\varepsilon}{ }^{-1} \hat{\alpha}$ corresponds to the difference between the square of the maximum SR for the portfolios which can be constructed from the $N$ assets and the $K$ factors and the square of the maximum SR for the portfolios which can be constructed from just the $K$ factors. Thus, a drop in the SR of the K-factor tangency portfolio, which indicates poorer economic performance of the model, is associated with an increase in $\operatorname{SR}(\hat{\alpha})$ and in the GRS test statistic.

The GRS test confidently rejects all models at extremely low p-values. Fama and French (2012) and Griffin (2002) derive the same conclusion. However, we also find that the GRS statistics clearly favour lower pricing errors of multifactor models with size effect. Model (D) in all panels yields a better description of excess returns on global portfolios than the benchmark models (A)-(C). Compared with the original three-factor model, its modified version with small-stock and big-stock value factors leads to a drop in the GRS statistic from 3.84 to 2.37 and in the unexplained Sharpe ratio from 0.64 to 0.54 . Low improvement in the adjusted $\bar{R}_{O L S}^{2}$ statistic reflects the high power of tests. For value portfolios, the models capture on average between $82 \%$ 
and $96 \%$ of the time-series variation in returns. Analogously, the modified version of the four-factor model with small-stock and big-stock momentum factors generates an improvement in the GRS and $\operatorname{SR}(\alpha)$ statistics.

Overall, our results show that the size-effect models are formally rejected, but this rejection reflects high power of asset pricing tests. Modified models fare better than the benchmarks and do a reasonable job in explaining intertemporal variation in global excess returns.

\subsection{Cross-sectional asset pricing tests with global portfolios}

In what follows we discuss cross-sectional results obtained with global size-, value-, and momentum-sorted portfolios. We study first the dispersion in risk exposures of value and momentum portfolios. Then we ask what factors are priced in the crosssection of returns.

\subsubsection{Risk exposures of global value and momentum portfolios}

Table 4 shows the estimated betas for the $5 \times 5$ sort of global portfolios on size and BE/ME (momentum) over the November 1990 to July 2013 period obtained from multiple time-series regressions of portfolio returns on the factors in Equations (6) and (7), respectively. We focus our attention on the cross-section of value (momentum) betas and their small-stock and big-stock components for value (momentum) portfolios. The structure of the betas matrices is similar to the presentation in Table 2. Column V$\mathrm{G}(\mathrm{W}-\mathrm{L})$ at the right edge reports differences between extreme value (winner) and extreme growth (loser) in each size category; the bottom row S-B reports the differences between the smallest and the largest portfolios in each BE/ME (past shortterm performance) category. Bold faces highlight significant estimates. T-ratios 
associated with the V-G (W-L) strategy are obtained from time-series regressions of excess returns on extreme value (winner) over extreme growth (loser) portfolios in each size category on a constant and the respective risk factors. Analogously, $t$-ratios associated with the S-B strategy are obtained from time-series regressions of excess returns on the smallest over the biggest stocks in each BE/ME (past short-term performance) category on a constant and the respective risk factors.

\section{[Insert Table 4 here]}

Two points are particularly important. First, the spreads in the HMLS betas exceed those in the HMLB betas in economic and statistical terms. Moreover, the spread in the HMLS betas increases from growth to value and from big to small stocks, while the HMLB betas show an opposite pattern with spreads increasing from small to big and from value to growth portfolios. We take this to be evidence that sensitivities to the HMLS factor are the drivers behind the cross-section of average returns of stock portfolios formed on size and $\mathrm{BE} / \mathrm{ME}$, while there is a zero or negative relation between expected excess stock returns and their HMLB betas. Second, low BE/ME stocks tend to offer insurance, while high BE/ME stocks hide statistically grounded exposures to fluctuations in the small-stock value factor, in contrast to the big-stock value betas.

Turning to the right half of the table, past winner stocks have higher WML and WMLS betas than past loser stocks independently of firm size. Most interestingly, the spread in the WMLS betas is generally declining from past winners to past losers and from small to big stocks and thus reminds us of a prevalent pattern in the cross-section of average

momentum returns in Table 2. By contrast, both the WML and WMLB betas tend to increase from past winners to past losers and from small to big stocks. Finally, the 
negative betas of loser (winner) stocks are indicative of their hedging value (riskiness). In sum, qualitative differences in the value and momentum betas in Table 4 are indicative of a tight economic relation between average returns and the small-stock value and momentum betas as opposed to their big-stock beta counterparts. To test this hypothesis, we examine the power of various beta representations to explain the crosssection of average global portfolio returns.

\subsubsection{Risk premia on global value portfolios}

We discuss first the findings for global value portfolios; subsequently, we summarize the results for global momentum portfolios and both stock categories jointly. ${ }^{10}$ Table 5 presents the baseline asset pricing results of estimating the empirical specifications in (A) the CAPM, (B) three-factor Fama-French, (C) four-factor Carhart, and (D) the modified Fama-French model with decomposed HML factor using 25 global size and BE/ME sorted portfolios described above. The models are provided in Equations (3)(6) above. The table reports the second-stage Fama-MacBeth (1973) estimates of the risk prices along with Shanken (1992) corrected $t$-statistics and measures of fit using the OLS and GLS estimation procedures.

\section{[Insert Table 5 here]}

The anatomy of our findings is quite transparent. The standard CAPM in column (A) of the table fails to explain the cross-sectional pattern in average returns on global portfolios sorted on size and book-to-market. An asset with a beta of 1.0 promises on average a premium of $6.21 \%$ p.a. according to the OLS. The respective GLS estimate of $5.62 \%$ p.a. corresponds to the actual mean market excess return in the sample of

\footnotetext{
${ }^{10}$ These results are representative for regional equity markets which are summarized in Section 4.3.
} 
5.6\% p.a. even more precisely. ${ }^{11}$ Pricing errors are yet too high to fit the data. The regression produces a negative measure of fit of $-39 \%$ for OLS and $-34 \%$ for GLS, which implies that the model has less explanatory power than a mechanical prediction of constant average returns across assets.

The original three-factor Fama-French (1993) model in column (B) is more successful due to the informational content of the HML betas. De Moor and Sercu (2013a) similarly find that the SMB factor lacks power in picking the return differentials across stocks of different size classes. Compared to the CAPM, the pricing errors are substantially lower while the fit is much higher with an associated adjusted crosssectional $\bar{R}_{\text {OLS }}^{2}$ of $45 \%$. The negative sample counterpart of the cross-sectional GLS $R^{2}$ cannot be interpreted directly as model failure but is interesting to look at as a normalized goodness-of-fit measure in relative terms (Lewellen et al. (2010)). Indeed, the GLS estimate of the HML risk premium is related closer to the mean return on the HML factor of about $4.75 \%$ p.a.

The results for the four-factor Carhart (1997) model in column (C) are indicative of a significant positive risk premium for covariance with the value and momentum factors. Whereas the GLS estimates generally correspond more precisely to the average factor returns as the factors are traded, the OLS estimate of the WML risk premium is about three times as high as its expected return.

Finally, column (D) gives the results of a modified Fama-French model with smallstock and big-stock HML components. There are strong benefits from taking the size effect in value factor into account. In the OLS case the $\bar{R}_{\text {OLS }}^{2}$ increases from $54 \%$ to

\footnotetext{
${ }^{11}$ Note that means in Table 1 are given in monthly percentage points.
} 
roughly $70 \%$ as we move from (C) to (D). Even more striking are the advantages of the new specification compared to the original three-factor model—and this is, in fact, a fare horse race as the information set underlying the right-hand-side (RHS) variables is the same across both representations. In economic but also statistical terms, small-stock value betas emerge as the key driver of the model. On contrary, we find no feedback of HMLB exposures on average stock returns. These results are pronounced even stronger in the lower panel. The GLS risk premium on the HMLS factor of $7.3 \%$ p.a. is economically reasonable and closely related to its sample mean of $7.2 \%$ in annual terms. Note that the modified Fama-French specification is the only model with a positive $\rho_{G L S}^{2}$ measure.

Figure 1 provides a visual summary of these estimates. It plots the predicted average excess return on the horizontal axis and the actual sample average excess return on the vertical axis. The four diagrams correspond clockwise from top left to (A) the CAPM, (B) three-factor Fama-French, (C) four-factor Carhart, and (D) four-factor model with the Mkt, SMB, HMLS and HMLB factors. The digits in the figures denote the 25 global size and BE/ME- portfolios with a first digit standing for size (1 for smallest and 5 for biggest stocks) and the second digit standing for BE/ME (1 for extreme growth and 5 for extreme value). Under perfect fit, all points would fall on the displayed 45 degree line.

\section{[Insert Figure 1 here]}

The figure demonstrates the importance of size effect for a cross-section of returns. As previously noted, we find particularly interesting the comparison of the modified sizeeffect model to the original three-factor model, as both specifications effectively rely on 
the same information set to construct the explanatory variables. Overall, the crosssectional regressions in Table 5 indicate that decomposing the value factor into its small-stock and big-stock components leads to more accurate pricing, greater explanatory power, and generally lower pricing errors. These results reflect a tight relation between equity premia and the small-stock value spread.

\subsubsection{Risk premia on global momentum portfolios}

In this section, we evaluate the cross-sectional performance of the modified Carhart model in Equation (7) for average returns on global momentum portfolios. To form a basis for comparison, Table 6 presents the baseline results for (A) the CAPM, (B) three-factor Fama-French, and (C) four-factor Carhart models using $5 \times 5$ sort of global portfolios on size and momentum. All estimates and pricing errors are given in \% p.a.

\section{[Insert Table 6 here]}

The main results are analogous to our findings for value portfolios. We summarize them briefly below. The OLS estimates in the upper panel of the table tend to generally overestimate the risk premia on common risk factors, while the GLS estimates are more closely fitting the sample means. For the ease of comparison, the global equity premium is on average about 5.64\% p.a.; the SMB, HML and WML factors have means of $0.84 \%, 4.8 \%$, and $7.68 \%$ in annual terms, respectively; the WMLS and WMLB factors promise an average rate of return of $10.20 \%$ and $5.04 \%$ per year. While the single-beta CAPM and a three-factor model do a very poor job of explaining sizeand momentum-sorted portfolios, the fit of the four-factor model is materially better.

Lower standard errors induce an increase in the $\bar{R}_{\text {OLS }}^{2}$ statistic to about 66\%, while the $\rho_{G L S}^{2}$ turns positive. Column (D) in the table demonstrates most strikingly, that the 
standard Carhart model is clearly outperformed by our alternative specification which explains about $84 \%$ of the cross-sectional variation in the data. In line with our intuition and the evidence from value portfolios, the explanatory ability of the modified Carhart model is stemming from the WMLS, not the WMLB factor.

\subsubsection{Joint pricing of size-, value-, and momentum-sorted portfolios}

To price value and momentum portfolios jointly, we employ a specification in Equation (8) which combines the size-effect decompositions of the HML and WML factors in a six-factor representation. Table 7 is organised in a similar fashion as Tables 5 and 6 with the last column presenting the baseline cross-sectional results for the modified Fama-French/Carhart model with HML split into HMLS and HMLB and WML split into WMLS and WMLB.

\section{[Insert Table 7 here]}

Global asset pricing tests with a large cross-section of 50 portfolios containing 25 sizeand value- and 25 size- and momentum-sorted stocks in Table 7 give strong support for the ability of small-stock value and momentum components to reflect common risks on equity markets. The model beats the benchmarks and explains close to $80 \%$ of the cross-sectional variation in global size-, value- and momentum-sorted stocks. The

respective $\overline{R_{\text {oLs }}^{2}}$ measures vary between 52\% for Asia Pacific and 88\% for Europe.

To wrap up, our analysis points out that disentangling the risk sources associated with the size effect in common risk factors is important for cross-sectional asset pricing tests independent of the underlying characteristics the portfolio formation is based on. Equity premia are, in general, tightly linked to common risk factors constructed on the basis of small stocks. 


\subsection{Asset pricing tests of international integration}

Inspired by the international asset pricing theory and advanced financial market liberalization, a number of studies document the importance of global or world risk factors for pricing of domestic returns (Harvey (1991), Campbell and Hamao (1992), and Hou et al. (2011)). In this vein, Nitschka (2010) argues that one (national) discount factor should price any (international) asset. This view is, however, not uncontroversial. Other studies conclude that local factors matter more for regional asset prices than their global equivalents. For example, Griffin (2002) finds that country-specific versions of the three-factor Fama-French model provide a better description of international stock returns compared to a global model. He shows that adding foreign factors in a model with local factors deteriorates the general model fit. Fama and French (2012) similarly reject global factors in asset pricing models for region-specific returns in time-series tests.

In view of this debate, we revisit the question of financial market integration with a particular interest on global and local versions of the size-effect models. Our results indicate that global small-stock risk factors are significantly priced but regional models lead to more accurate portfolio pricing. This result is important both for practical applications such as calculations of the required rate of return and asset evaluations but also from an economic perspective. These findings may be taken as evidence of incomplete financial integration or signal model misspecification.

\subsubsection{Time-series evidence}

Our time-series tests in Tables 8 and 9 for international value and momentum portfolios resemble the findings in Fama and French (2012) and are therefore not discussed here 
in details. In case of North America and Asia Pacific, the GRS rejections reflect high power of tests. In case of European value portfolios and Japan, a sizable drop in the GRS statistics into the left tail of distribution should be treated with caution in view of high $p$-values. In general, these tests verify that domestic factor models explain more intertemporal variation in returns and produce lower pricing errors than models with global factors. Moreover, in line with evidence for global portfolios discussed above, this out-of-sample exercise consistently supports superior performance of our sizeeffect specifications over the traditional benchmarks.

\section{[Insert Tables 8 and 9 here]}

\subsubsection{Cross-sectional evidence}

Table 10 shows a summary of cross-sectional asset pricing tests for international value and momentum portfolios with regional and global factors. ${ }^{12}$

\section{[Insert Table 10 here]}

Interestingly, our cross-sectional tests put the time-series evidence into perspective: The advantages of local models are economically minor as the fit and the pricing errors are broadly similar between global and regional model varieties. Only in the case of value portfolios in Asia Pacific, regional factors clearly outperform their global counterparts, while the opposite, though to a smaller extent, is true for North America. A possible interpretation of these findings is an advanced (early) stage of financial integration in North America (Asia Pacific). In addition, the international tests-except for Japanreinforce our conclusion that models reflecting the size effect in common risk factors consistently outperform conventional benchmarks. Table 11 further supports that local but also global versions of the small-stock value and momentum factors are

\footnotetext{
${ }^{12}$ The online appendix contains detailed results.
} 
significantly priced in international returns across all regions but Japan. Taken together, these tests suggest that global models are not necessarily a bad tool to explain regional markets but regional models, on average, promise a better description of the data.

\section{[Insert Table 11 here]}

\subsection{Robustness and further results}

We conduct a number of robustness checks: Following Lewellen et al. (2010) we expand the set of test assets to relax a strong factor structure of the original portfolio returns. We test the sensitivity of our results to the choice of sample size and employ an additional set of U.S. test assets available since 1927. We run regressions over different sample periods and vary the number of test assets; we allow the betas to vary over time and estimate the models in- and out-of-sample for each region as well as globally; guided by Jagannathan and Wang (1998) we use univariate betas as regressors; finally, we experiment with alternative plausible model specifications which feature size effect in common risk factors. Our conclusions remain qualitatively unaffected. These results are readily available upon request but not presented here in detail to save space. The main points can be summarized as follows.

\subsubsection{Sensitivity to the choice of test assets and sample periods}

To make our asset pricing tests more convincing we expand the set of test portfolios. We follow the recommendation of Lewellen et al. (2010) and work with 30 U.S. industry portfolios to reduce the commonality effects in portfolios sorted on firm characteristics. We also include U.S. portfolios sorted on other characteristics—cash flow-to-price, dividend-to-price, and earnings-to-price sorts. Availability of U.S. data over a longer sample period allows us to repeat the tests over a time span from July 
1927 to December 2012. We do sample splits as is standard in the literature and reevaluate the models before and after 1963; we proceed mechanically and split the sample in the middle; in addition, we study various alternative time intervals which have been considered in other studies. We find that the performance of modified models with size effect in common risk factors is generally more stable for momentum than value portfolios. However, the small-stock components of both value and momentum factors remain priced consistently in our tests. Specifications in Equations (6)-(8) outperform the benchmark models in (3)-(5) throughout in line with our baseline findings.

\subsubsection{Excluding micro-cap stocks}

We follow Fama and French (2012) and re-run the time-series and cross-sectional regressions on a smaller set of test assets based on $4 \times 5$ sorts by size, BE/ME, and momentum as small stocks are known to be particularly difficult to price (for average pricing errors see also Figures 1-3). Indeed, we find that all models do to some extent better but the size effect specifications continue to outperform.

\subsubsection{Univariate betas}

Betas are usually estimated from multiple regressions of asset returns on factors and are hence referred to as multivariate or multiple regression betas. Unless factors are uncorrelated, the first-stage regression might generate beta estimates which are unreliable. To guard against this possibility we follow Jagannathan and Wang (1998) and re-estimate our models with so called univariate or simple regression betas estimated for each factor separately. We observe no qualitative change in the outcome.

\subsubsection{Time-varying betas and out-of-sample evidence}


In a next exercise, instead of assuming fix betas over the full sample we allow betas to vary over time. First, we obtain betas in rolling time-series regressions over a 6-year or 72-month period. Then we run a series of in-sample cross-sectional regressions of average returns over the same 6-year or 72-month period on these betas. Secondly, we test the predictive ability of beta estimates in out-of-sample tests which relate betas estimated over a 6-year or 72-month period to average returns over the next 6-year or 72-month period. Our results turn out representative for other sample period lengths. ${ }^{13}$ In a further experiment, we run overlapping cross-sectional regressions relating timevarying betas to next-month returns. Even this kind of exercise supports the view that factors constructed on the basis of small stocks are important to capture commonalities in returns. However, this test generally leads to a substantial increase in the magnitude of pricing errors in any model we consider.

\subsubsection{Further specifications}

In attempts to further investigate the sensitivity of our results, we consider a number of additional model specifications. For value portfolios, we test (i) a three-factor model with Mkt, SMB and HMLS; (ii) a four-factor model with Mkt, SMB, WML, and HMLS; (iii) an alternative four-factor model with Mkt, SMB, HMLS and WMLS; and (iv) a five-factor model with Mkt, SMB, WML, HMLS and HMLB. In a similar fashion, we opt for alternative versions of factor models for momentum portfolios. Our main conclusions remain valid.

\section{Relation to funding liquidity risk}

Asness et al. (2013) suggest that funding liquidity risk can explain several patterns in value and momentum return premia across diverse markets and asset classes. While the

\footnotetext{
${ }^{13}$ Fama and MacBeth (1973) recommend using intervals of more than four years.
} 
authors find only modest links between value and momentum and macroeconomic variables such as the business cycle, consumption, and default, they show that there is a significant relation between liquidity risk and value and momentum strategies. Furthermore, they show that in contrast to market liquidity, the primary source of fluctuations in value and momentum returns comes from funding liquidity, whose importance has increased in particular since the funding crisis of 1998 (Brunnermeier et al. (2009)). To this end, this section investigates the role of funding risk for value and momentum and the relation between funding liquidity and small-stock risk factors.

\section{1 $\quad$ Funding liquidity proxies}

We follow Brunnermeier and Pedersen (2009) and consider two alternative measures of funding illiquidity. The first is the Treasury-Eurodollar (TED) spread which is computed as the difference between the local 3-month London Interbank Offered Rate (LIBOR) market interest rate and the local three-month government rate. As the LIBOR rate reflects uncollateralized lending in the interbank market which is subject to default risk, the TED spread mirrors the willingness of banks to provide funding. For each region, we use the LIBOR rate based on local currency, i.e. for North America the U.S. Dollar $^{14}$, for Europe the Euro since 1999 and Deutsche Mark for the period prior to 1999, for Japan the Japanese Yen, and for Asia Pacific excluding Japan the Australian Dollar as LIBOR interest rates for Hong Kong, Singapore, and New Zealand either do not exist or are only available for a shorter time span. These data are from the Federal Reserve Bank of St. Louis as stated by the British Bankers’ Association. The series for Germany are from the EconStats database. The local risk-free rates are from the

\footnotetext{
${ }^{14}$ The series based on Canadian Dollar are disconnected.
} 
International Financial Statistics of the IMF. Global TED spread is constructed as a simple average of region-specific TED spreads.

As another proxy of funding liquidity we use the implied volatility of the S\&P 500 stock index option prices from the Chicago Board Options Exchange, denoted as VIX. The VIX index emerges as a key measure of expected near-term market volatility and a barometer of investor sentiment (e.g. Ang et al. (2006) and Adrian and Rosenberg (2008)). Brunnermeier and Pedersen (2009) note that funding constraints are associated with global volatility increases. Menkhoff et al. (2012) similarly point out that it is hard to disentangle volatility and liquidity effects precisely as these concepts are intimately related. Note that TED spread and VIX index are, in fact, measures of funding illiquidity as widening spreads and high volatility indicate liquidity decrease.

Asness et al. (2013) look, in addition, at the spread between interest rates swaps and the risk-free rate as a further measure of funding liquidity. We obtain qualitatively similar results with the U.S. swap rates but do not include them into analysis as these data become available only in the 2000's and are not available for each region. Finally, we do not detect a robust significant relation as regards the Pastor and Stambaugh (2003) and Sadka (2006) ${ }^{15}$ market liquidity measures. This result is in line with Asness et al. (2013) who show that funding liquidity, as opposed to the market liquidity, is the primary key to profitability of value and momentum in international markets.

\section{$5.2 \quad$ Liquidity risk exposures}

We measure liquidity betas of value and momentum portfolios from multiple timeseries regressions analogously to the HMLS and WMLS betas in Table 4. Tables 12

\footnotetext{
${ }^{15}$ The Sadka (2006) liquidity factor is available for the period April 1983 through December 2008 on the WRDS.
} 
and 13 report the loadings of global and regional value and momentum portfolios for two measures of illiquidity which we use interchangeably: the global TED spread and the U.S. TED spread. Overall patterns in the cross-section of univariate betas, risk measures obtained from alternative multifactor specifications, and local liquidity risk proxies are qualitatively very similar.

\section{[Insert Tables 12 and 13 here]}

Interestingly, liquidity betas of value and momentum portfolios are typically in the interval between -1 and 1 ; low negative (high positive) betas signal high (low) liquidity risk for assets which generate low (high) returns in times of high illiquidity. Table 12 points out several differences in the risk structure of small versus big value and growth stocks. Generally, small value stocks reveal lower illiquidity betas, i.e. higher funding liquidity sensitivities, than their small growth counterparts. In stark contrast, big value stocks usually have higher illiquidity betas, i.e. lower funding liquidity sensitivities, than big growth counterparts. Thus, small-stock growth stocks offer higher excess returns when spreads widen and funding illiquidity goes up, while small-stock value stocks offer lower returns at those times. This picture reverses when we move to high $\mathrm{BE} / \mathrm{ME}$ segments. Among big stocks, growth stocks are typically riskier than the respective value stocks. These patterns emerge across different regions but are particularly strongly pronounced for global and European markets. The value-growth illiquidity spreads increase monotonically from -1.20 for small to 0.16 for big stocks in global markets, and from -2.10 to 0.18 in European markets. Analogously, the size spreads, i.e. beta differentials between small and big stocks, tend to increase from value to growth stocks. For example, the return on small-minus-big stocks strategy increases 
monotonically from -0.40 for value to 0.95 for growth stocks in global markets, and from -0.82 for value to 1.46 for growth stocks in European markets. We take this to be evidence that there are significant links between funding liquidity and equity markets, in general, and between funding liquidity risks and small-stock value premium, in particular. We find similar, albeit somewhat weaker evidence for momentum. The only exception is North America where we cannot detect lower betas for past winners against past losers portfolios.

This liquidity risk structure of size-, value-, and momentum-sorted portfolios has several implications which we investigate further. First, we expect a significant link between liquidity risk and the cross-section of equity excess returns as liquidity betas of value and momentum stocks share common patterns with their average returns. Second, we expect a tighter link between funding liquidity small-stock—as opposed to bigstock — value and momentum factors on the basis of a positive link between liquidity betas and small-stock value and momentum premia. Finally, if funding liquidity risk and small-stock risk factors are related, then positive (negative) HMLS betas of value (growth) stocks and positive (negative) WMLS betas of past winners (past losers) stocks should be associated with their negative (positive) illiquidity betas and signal therefore their low (high) returns during tensions in funding markets. We find strong support for each of these hypotheses.

Figure 2 plots the estimated LIQ betas against HMLS (WMLS) betas for global value (momentum) portfolios. Stocks with high HMLS (WMLS) betas tend to have systematically high liquidity risk exposures, i.e. negative illiquidity betas, whereas stocks with low HMLS (WMLS) betas tend to have systematically low liquidity risk 
exposures, i.e. positive illiquidity betas. When funding liquidity is measured by the global TED spread, the correlation between liquidity and small-stocks betas exceeds $45 \%$ for global value and $60 \%$ for global momentum portfolios in absolute terms. Taking the U.S. TED spread as a proxy for funding liquidity we find even stronger relation between HMLS (WMLS) and LIQ betas of more than 70\%, respectively, 55\% in absolute terms. At a regional level, we find similar qualitative inference. Using global, U.S., and local TED spreads as well as the VIX measure of illiquidity does not materially affect the results.

\section{[Insert Figure 2 here]}

These findings are indicative of a close relation between small-stock value and momentum factors and funding liquidity, and echo Lustig et al. (2011) show that there is a tight link between the $H M L_{F X}$ factor in currency markets and changes in global market volatility: High (low) interest rate countries tend to offer low (high) returns when equity volatility goes up. Thus, high (low) $H M L_{F X}$ betas of high (low) interest rate currencies adhere to low (high) volatility betas. In a related study, Menkhoff et al. (2012) find that similar mechanisms are at work between global volatility in foreign exchange markets and the cross-section of currency portfolio returns.

\subsection{Asset pricing tests with liquidity risk}

Asness et al. (2013) find that global funding liquidity risk can explain several patterns in value and momentum returns; however, they note that this systematic relation is identifiable only when value and momentum are examined jointly. Against this backdrop, we consider a large pool of test assets consisting of value and momentum portfolios jointly in our cross-sectional asset pricing tests with liquidity. 
First we re-estimate the modified Fama-French/Carhart specification in Equation (8) but replace HMLS and WMLS with a liquidity factor. The upper panel of Table 14 uses the global TED spread to proxy for liquidity; the lower panel employs the U.S. TED spread instead. As mentioned above, the TED spreads represent illiquidity since wider spreads signal worse liquidity. Finance theory predicts high returns on assets which fail to payoff in bad times when illiquidity goes up, so that illiquidity commands a negative price of risk.

\section{[Insert Table 14 here]}

Our findings in Table 14 consistently support the view that in months in which funding illiquidity increases value and momentum investments incur significant losses in global and regional markets except for Japan where the liquidity premium is estimated with a right sign but very imprecisely. Assets with a strong tendency to react to illiquidity provide an insurance service. As such assets are a valuable investment to hold, high demand drives up their prices and induces lower excess returns. We find a discount of roughly 2 to 5 percent per annum for illiquidity in the data which lines up with the estimates for volatility risks in foreign exchange markets documented in Lustig et al. (2011) and Menkhoff et al. (2013). Furthermore, our findings supplement the evidence in Kapadia (2011) who argues that the exposure to aggregate distress risk is the underlying source of the SMB and HML premia. He shows that lower returns on SMB and HML are typically accompanied by an increase in future failure rates.

It is interesting to note, however, that the model with funding liquidity-despite its significance-captures less variation in average returns than the original specification in Table 7. This result is intuitive as liquidity does not use any information on equity 
markets as opposed to factor mimicking portfolios of small stocks. Since liquidity is not observed directly but has to be estimated, it is not surprising that HMLS and WMLS have superior explanatory power for returns. In a horse race between small-stock risk factors and liquidity, the latter cannot replace the former as the pricing factor. Smallstock related risks dominate liquidity when both are included jointly as pricing factors in the model. In Table 15 we address the relative importance of small-stock risk factors and liquidity and re-estimate a modified Fama-French/Carhart specification in Equation (8) but include a liquidity factor in addition.

\section{[Insert Table 15 here]}

Our estimates generally confirm a loss of explanatory power for funding liquidity when the original factor mimicking portfolios for small-stock risk components enter a regression. In stark contrast, we find highly significant compensations for small-stock risk factors as in the baseline scenario.

Finally, to alleviate any concerns that these rusts might be spurious due to a link between the HMLS and WMLS betas of value and momentum stocks, on the one hand, and their liquidity betas, on the other hand, we repeat the above exercise with orthogonalized measures of factors (not reported). Our findings do not change. We obtain qualitatively similar effects when we use the VIX volatility ${ }^{16}$ or the local TED spreads to proxy for liquidity in regional markets. We hence conclude that funding liquidity can account for a fraction of small-stock value and momentum excess returns and thus provides a partial and incomplete explanation of our findings.

\section{Conclusions}

\footnotetext{
${ }^{16}$ Lustig et al. (2011) similarly find that volatility is priced in the cross-section of currency portfolios but cannot replace the HML factor in a horse race of models on foreign exchange markets.
} 
The fundamental conclusion of this study is that expected excess returns in developed equity markets vary in such a manner that is to a large extent described by factor mimicking portfolios constructed on the basis of small firms. We find that size of stocks underlying the two most studied risk factors in returns, i.e. value and momentum, entails significant implications for evaluations of risk-return relation in international equity markets. In particular, spreads in small-stock value factor loadings explain cross-sectional dispersion in average returns on value and growth stocks, while spreads in small-stock momentum factor loadings explain why recent winners on average have higher returns than recent losers. This finding indicates the presence of common risks related to small stocks.

With respect to tests of stock market integration, we document that global small-stock risk factors are significantly priced but regional models generally lead to more accurate portfolio evaluations. In practical applications, portfolio investment decisions are best performed by means of local asset pricing models which feature the size effect in common risk factors.

Finally, we show that small-stock value and momentum profits incur losses in months when funding liquidity collapses and global risk appetite experiences its hikes. To the extent that value and momentum spreads are related to funding liquidity risks, our findings reinforce the view that size characteristics capture systematic economy-wide risks. 


\section{References}

Ang, A., Hodrick, R.J., Xing, Y., Zhang, X., 2006. The Cross-Section of Volatility and Expected Returns. Journal of Finance 61, 259-299.

Asness, C.S., 1997. The Interaction of Value and Momentum Strategies. Financial Analysts Journal 53, 29-36.

Asness, C.S., Moskowitz, T.J., Pedersen, L.H., 2013. Value and Momentum Everywhere. Journal of Finance 68, 929-985.

Banz, R.W., 1981. The Relationship between Return and Market Value of Common Stocks. Journal of Financial Economics 9, 3-18.

Berk, J.B., Green, R.C., Naik, V., 1999. Optimal Investment, Growth Options, and Security Returns. Journal of Finance 54, 1553-1607.

Brunnermeier, M.K., Nagel, S., Pedersen, L.H., 2009. Carry Trades and Currency Crashes. NBER Macroeconomics Annual 2008, 23, Cambridge, MA, 313-347.

Campbell, J.Y., Hamao, Y., 1992. Predictable Stock Returns in the United States and Japan: A Study of Long-Term Capital Market Integration. Journal of Finance 47, 43-69.

Carhart, M.M., 1997. On Persistence in Mutual Fund Performance. Journal of Finance 52, 57-82.

Chan, K.C., Chen, N., Hsieh, D.A., 1985. An Explanatory Investigation of the Firm Size Effect. Journal of Financial Econometrics 14, 451-471.

Chen, L., Petkova, R., Zhang, L., 2008. The Expected Value Premium. Journal of Financial Economics 87, 269-280.

Cochrane, J.H., 1996. A Cross-Sectional Test of an Investment-Based Asset Pricing Model. Journal of Political Economy 104, 572-621.

Cochrane, J.H., 2005. Asset Pricing, Revised Edition. Princeton University Press.

De Moor, L., Sercu, P., 2013a. The Smallest Firm Effect: An International Study. Journal of International Money and Finance 32, 129-155.

De Moor, L., Sercu, P., 2013b. The Smallest Stocks are not Just Smaller: Global Evidence. European Journal of Finance, forthcoming.

Fama, E.F., French, K.R., 1993. Common Risk Factors in the Returns on Stocks and Bonds. Journal of Financial Economics 33, 3-56. 
Fama, E.F., French, K.R., 1995. Size and Book-to-Market Factors in Earnings and Returns. Journal of Finance 50, 131-155.

Fama, E.F., French, K.R., 2012. Size, Value, and Momentum in International Stock Returns. Journal of Financial Economics 105, 457-472.

Fama, E.F., MacBeth, J.D., 1973. Risk, Return, and Equilibrium: Empirical Tests. Journal of Political Economy 81, 607-636.

Gomes, J., Kogan, L., Zhang, L., 2003. Equilibrium Cross Section of Returns. Journal of Political Economy 111, 693-732.

Gibbons, M.R., Ross, S.A., Shanken, J., 1989. A Test of the Efficiency of a Given Portfolio. Econometrica 57, 1121-1152.

Griffin, J.M., 2002. Are the Fama and French Factors Global or Country Specific? Review of Financial Studies 15, 783-803.

Harvey, C.R., 1991. The World Price of Covariance Risk. Journal of Finance 46, 111157.

Heaton, J., Lucas, D., 2000. Portfolio Choice and Asset Prices: The Importance of Entrepreneurial Risk. Journal of Finance 55, 1163-1198.

Hong, H., Stein, J., Lim, T., 2000. Bad News Travels Slowly: Size, Analyst Coverage and the Profitability of Momentum Strategies. Journal of Finance 46, 111-157.

Hou, K., Karolyi, G.A., Kho, B.-C., 2011. What Factors Drive Global Stock Returns? Review of Financial Studies 24, 2527-2574.

Horowitz, J.L., Loughran, T., Savin, N.E., 2000. Three Analyses of the Firm Size Premium. Journal of Empirical Finance 7, 143-153.

Jagannathan, R., Wang, Z., 1998. An Asymptotic Theory for Estimating Beta-Pricing Models Using Cross-Sectional Regression. Journal of Finance 53, 1285-1309.

Jegadeesh, N., Titman, S., 1993. Returns to Buying Winners and Selling Losers: Implications for Stock Market Efficiency. Journal of Finance 48, 65-91.

Kan, R., Robotti, C., 2012. Evaluation of Asset Pricing Models Using Two-Pass CrossSectional Regressions. In: J.-C. Duan et al. (eds.), Handbook of Computational Finance, Springer Handbooks of Computational Statistics. Springer-Verlag Berlin Heidelberg.

Kan, R., Robotti, C., Shanken, J., 2013. Pricing Model Performance and the Two-Pass Cross-Sectional Regression Methodology. Journal of Finance, forthcoming. 
Kandel, S., Stambaugh, R.F., 1995. Portfolio Inefficiency and the Cross-Section of Expected Returns. Journal of Finance 50, 157-184.

Kapadia, N., 2011. Tracking Downside Distress Risk. Journal of Financial Economics 102, 167-182.

Keim, D.B., Stambaugh, R.F., 1986. Predicting Returns in the Stock and Bond Markets. Journal of Financial Economics 17, 357-390.

Lettau, M., Ludvigson, S., 2001. Consumption, Aggregate Wealth, and Expected Stock Returns. Journal of Finance 56, 815-849.

Lewellen, J., Nagel, S., 2006. The Conditional CAPM Does Not Explain Asset Pricing Anomalies. Journal of Financial Economics 82, 289-314.

Lewellen, J., Nagel, S., Shanken, J., 2010. A Skeptical Appraisal of Asset Pricing Tests. Journal of Financial Economics 96, 175-194.

Liew, J., Vassalou, M., 2000. Can Book-to-Market, Size and Momentum Be Risk Factors That Predict Economic Growth? Journal of Financial Economics 57, 221-245.

Lintner, J., 1965. The Valuation of Risk Assets and the Selection of Risky Investments in Stock Portfolios and Capital Budgets. Review of Economics and Statistics 47, 13-37.

Lustig, H., Roussanov, N., Verdelhan, A., 2011. Common Risk Factors in Currency Markets. Review of Financial Studies 24, 3731-3777.

Menkhoff, L., Sarno, L., Schmeling M., Schrimpf, A., 2012. Carry Trades and Global Foreign Exchange Volatility. Journal of Finance 67, 681-718.

Nitschka, T., 2010. Cashflow News, the Value Premium and an Asset Pricing View on European Stock Market Integration. Journal of International Money and Finance 29, 1406-1423.

Pastor, L., Stambaugh, R.F., 2003. Liquidity Risk and Expected Stock Returns. Journal of Political Economy 111, 642-685.

Petkova, R., Zhang, L., 2005. Is Value Riskier Than Growth? Journal of Financial Economics 78, 187-202.

Reinganum, M.R., 1981. Misspecification of Capital Asset Pricing: Empirical Anomalies Based on Earnings Yields and Market Values. Journal of Financial Economics 9, 19-46.

Sadka, R., 2006. Momentum and Post-Earnings-Announcement Drift Anomalies: The Role of Liquidity Risk. Journal of Financial Economics 80, 309-349. 
Schwert, G., 1983. Indexes of Stock Prices from 1802 to 1987. Journal of Business 63, 399-426.

Shanken, J., 1992. On the Estimation of Beta-Pricing Models. Review of Financial Studies 5, 1-33.

Sharpe, W.F., 1964. Capital Asset Prices: A Theory of Market Equilibrium Under Conditions of Risk. Journal of Finance 19, 425-442.

van Dijk, A.M., 2011. Is Size Dead? A Review of the Size Effect in Equity Returns. Journal of Banking and Finance 35, 3263-3274.

Yogo, M., 2006. A Consumption-Based Explanation of Expected Stock Returns. Journal of Finance 61, 539-580.

Zhang, L., 2005. The Value Premium. Journal of Finance 60, 67-103.

Zhang, C., 2008. Decomposed Fama-French Factors for the Size and Book-to-Market Effects. Unpublished Manuscript. 
Table 1: Global Common Risk Factors

The table shows monthly average returns, standard deviations (in \%), and correlation coefficients for global common risk factors. Mkt, SMB, and HML are the standard market, size, and value factors of Fama and French (1993); WML is the momentum factor of Carhart (1997); HMLS, HMLB, WMLS and WMLB are constructed following Fama and French (2012) as SV-SG, BV-BG, SW-SL, and BW-BL, respectively. Bold faces highlight significance at the $5 \%$ level. The sample period is November 1990 - July 2013.

\begin{tabular}{lccccccccc}
\hline \hline & \multirow{2}{*}{ Mean } & \multirow{2}{*}{ Std. } & \multicolumn{10}{c}{ Correlation } \\
\cline { 4 - 10 } & & Mkt & SMB & HML & WML & HMLS & HMLB & WMLS \\
\hline Mkt & 0.47 & 4.37 & 1.00 & & & & & & \\
SMB & 0.07 & 2.09 & -0.01 & 1.00 & & & & & \\
HML & $\mathbf{0 . 4 0}$ & 2.37 & $\mathbf{- 0 . 1 3}$ & $\mathbf{- 0 . 1 8}$ & 1.00 & & & & \\
WML & $\mathbf{0 . 6 4}$ & 4.06 & $\mathbf{- 0 . 2 3}$ & $\mathbf{0 . 1 7}$ & $\mathbf{- 0 . 2 5}$ & 1.00 & & & \\
HMLS & $\mathbf{0 . 6 0}$ & 2.63 & $\mathbf{- 0 . 3 8}$ & $\mathbf{- 0 . 2 8}$ & $\mathbf{0 . 9 0}$ & -0.11 & 1.00 & & \\
HMLB & 0.19 & 2.65 & $\mathbf{0 . 1 3}$ & -0.05 & $\mathbf{0 . 9 0}$ & $\mathbf{- 0 . 3 4}$ & $\mathbf{0 . 6 1}$ & 1.00 & \\
WMLS & $\mathbf{0 . 8 5}$ & 3.94 & $\mathbf{- 0 . 2 6}$ & 0.12 & $\mathbf{- 0 . 2 3}$ & $\mathbf{0 . 9 5}$ & -0.08 & $\mathbf{- 0 . 3 3}$ & 1.00 \\
WMLB & 0.42 & 4.54 & $\mathbf{- 0 . 1 9}$ & $\mathbf{0 . 2 0}$ & $\mathbf{- 0 . 2 5}$ & $\mathbf{0 . 9 6}$ & $\mathbf{- 0 . 1 3}$ & $\mathbf{- 0 . 3 1}$ & $\mathbf{0 . 8 3}$ \\
\hline \hline
\end{tabular}

Table 2: Global Size, Value and Momentum Sorted Portfolios

The table shows monthly average excess returns and standard deviations (in \%) on 25 global portfolios formed on size and BE/ME or size and momentum. The sample period is November 1990 - July 2013.

\begin{tabular}{lcccccccccccc}
\hline \hline & \multicolumn{1}{c}{ Mean } & \multicolumn{1}{c}{ Value } \\
\hline & \multicolumn{1}{c}{ G } & 2 & 3 & 4 & V & V-G & G & 2 & 3 & 4 & V \\
\hline & G & Std. \\
\hline S & 0.14 & 0.43 & 0.71 & 0.77 & 1.08 & 0.94 & 5.81 & 5.42 & 5.04 & 4.61 & 4.36 \\
2 & 0.17 & 0.46 & 0.59 & 0.66 & 0.79 & 0.63 & 5.74 & 5.15 & 4.66 & 4.41 & 4.52 \\
3 & 0.29 & 0.41 & 0.55 & 0.60 & 0.75 & 0.46 & 5.65 & 5.14 & 4.62 & 4.43 & 4.64 \\
4 & 0.42 & 0.46 & 0.53 & 0.61 & 0.70 & 0.28 & 5.53 & 4.61 & 4.52 & 4.46 & 4.79 \\
B & 0.36 & 0.40 & 0.50 & 0.54 & 0.52 & 0.17 & 4.53 & 4.25 & 4.44 & 4.47 & 5.44 \\
S-B & -0.21 & 0.02 & 0.20 & 0.23 & 0.56 & & & & & & \\
\hline & \multicolumn{1}{c}{} & \multicolumn{4}{c}{ Momentum } & & & & & \\
\hline & L & 2 & 3 & 4 & W & W-L & L & 2 & 3 & 4 & W \\
\hline S & 0.11 & 0.64 & 0.77 & 1.10 & 1.51 & 1.40 & 6.38 & 4.35 & 3.94 & 4.06 & 5.38 \\
2 & 0.14 & 0.50 & 0.57 & 0.79 & 1.10 & 0.96 & 6.63 & 4.61 & 4.16 & 4.19 & 5.46 \\
3 & 0.28 & 0.50 & 0.57 & 0.61 & 0.87 & 0.59 & 6.60 & 4.85 & 4.25 & 4.15 & 5.47 \\
4 & 0.26 & 0.48 & 0.56 & 0.58 & 0.89 & 0.63 & 6.54 & 4.75 & 4.19 & 4.21 & 5.29 \\
B & 0.14 & 0.37 & 0.43 & 0.58 & 0.62 & 0.48 & 6.25 & 4.57 & 4.08 & 4.16 & 5.27 \\
S-B & -0.02 & 0.27 & 0.34 & 0.53 & 0.89 & & & & & & \\
\hline \hline
\end{tabular}


Table 3: Time Series Asset Pricing Tests with Global Value and Momentum Portfolios The table reports a summary of the first-stage Fama-MacBeth (1973) regressions using 25 global portfolios formed on size and $\mathrm{BE} / \mathrm{ME}$ or size and momentum. The tested models are (A) CAPM; (B) three-factor Fama-French (1993); (C) four-factor Carhart (1997); (D) modified Fama-French model for value; (A) CAPM; (B) three-factor FamaFrench (1993); (C) four-factor Carhart (1997); (D) modified Carhart model for momentum; and (A) CAPM; (B) three-factor Fama-French (1993); (C) four-factor Carhart (1997); (D) modified Fama-French/Carhart model for value and momentum portfolios. The GRS statistic tests whether all intercepts in a set of 25 or 50 regressions are zero; p-val. is the associated p-value; $|\alpha|$ is the average absolute intercept; $s(\alpha)$ is the average standard error of the intercepts; $\operatorname{SR}(\alpha)$ is the Sharpe ratio for the intercepts; and $\bar{R}_{\text {OLS }}^{2}$ is the average OLS $R^{2}$ adjusted for the degrees of freedom. With 25 portfolios and 273 monthly returns, critical values of the GRS statistic for all models are 90\%: 1.41; 95\%: 1.55; 99\%: 1.85. With 50 portfolios and 273 monthly returns, critical values of the GRS statistic for all models are 90\%: 1.31; 95\%: 1.41; 99\%: 1.62. The sample period is November 1990 - July 2013.

\begin{tabular}{lcccccc}
\hline \hline & GRS & $\mathrm{p}$-val. & $|\alpha|$ & $\mathrm{s}(\alpha)$ & $\mathrm{SR}(\alpha)$ & $\bar{R}_{\text {OLS }}^{2}$ \\
\hline \multicolumn{7}{c}{ Value } \\
\hline (A) & 4.15 & {$[0.00]$} & 0.18 & 0.12 & 0.65 & 0.82 \\
(B) & 3.84 & {$[0.00]$} & 0.11 & 0.06 & 0.64 & 0.95 \\
(C) & 3.46 & {$[0.00]$} & 0.09 & 0.07 & 0.63 & 0.96 \\
(D) & 2.37 & {$[0.00]$} & 0.10 & 0.06 & 0.54 & 0.96 \\
\hline \multicolumn{7}{c}{ Momentum } \\
\hline (A) & 4.94 & {$[0.00]$} & 0.31 & 0.14 & 0.71 & 0.78 \\
(B) & 5.27 & {$[0.00]$} & 0.32 & 0.11 & 0.75 & 0.88 \\
(C) & 4.45 & {$[0.00]$} & 0.13 & 0.07 & 0.71 & 0.94 \\
(D) & 3.71 & {$[0.00]$} & 0.11 & 0.07 & 0.67 & 0.95 \\
\hline \multicolumn{7}{c}{ Value and Momentum } \\
\hline (A) & 4.17 & {$[0.00]$} & 0.25 & 0.13 & 0.97 & 0.80 \\
(B) & 3.93 & {$[0.00]$} & 0.22 & 0.09 & 0.97 & 0.92 \\
(C) & 3.47 & {$[0.00]$} & 0.11 & 0.07 & 0.94 & 0.95 \\
(D) & 2.49 & {$[0.00]$} & 0.09 & 0.07 & 0.85 & 0.96 \\
\hline \hline
\end{tabular}


Table 4: Betas of Global Value and Momentum Portfolios

The table shows the estimated HML ( $\beta_{\text {нмL }}$ ), HMLS ( $\left.\beta_{\text {нмLS }}\right)$ and HMLB ( $\beta_{\text {нмLB }}$ ) betas of 25 global portfolios formed on size and $\mathrm{BE} / \mathrm{ME}$ and WML $\left(\beta_{\text {WML }}\right)$, WMLS $\left(\beta_{\text {WMLS }}\right)$ and WMLB $\left(\beta_{W M L B}\right)$ betas of 25 global portfolios formed on size and momentum. Estimates significant at the 5\% level are highlighted in bold face. The sample period is November 1990 - July 2013.

\begin{tabular}{|c|c|c|c|c|c|c|c|c|c|c|c|c|}
\hline & $\mathrm{G}$ & 2 & 3 & 4 & $\mathrm{~V}$ & $\mathrm{~V}-\mathrm{G}$ & $\mathrm{L}$ & 2 & 3 & 4 & $\mathrm{~W}$ & W-L \\
\hline & \multicolumn{6}{|c|}{ HML Beta } & \multicolumn{6}{|c|}{ WML Beta } \\
\hline $\mathrm{S}$ & -0.44 & -0.20 & 0.01 & 0.25 & 0.46 & 0.90 & -0.59 & -0.17 & -0.01 & 0.13 & 0.34 & 0.93 \\
\hline 2 & -0.46 & -0.13 & 0.11 & 0.43 & 0.63 & 1.09 & -0.68 & -0.21 & -0.02 & 0.16 & 0.42 & 1.10 \\
\hline 3 & -0.56 & -0.14 & 0.27 & 0.49 & 0.67 & 1.23 & -0.66 & -0.26 & -0.03 & 0.16 & 0.49 & 1.15 \\
\hline 4 & -0.55 & 0.07 & 0.30 & 0.48 & 0.70 & 1.25 & -0.70 & -0.27 & -0.04 & 0.20 & 0.54 & 1.24 \\
\hline B & -0.61 & -0.06 & 0.20 & 0.40 & 0.60 & 1.21 & -0.70 & -0.27 & 0.02 & 0.29 & 0.64 & 1.34 \\
\hline \multirow[t]{2}{*}{ S-B } & 0.17 & -0.14 & -0.19 & -0.15 & -0.13 & & 0.11 & 0.10 & -0.03 & -0.16 & -0.30 & \\
\hline & \multicolumn{6}{|c|}{ HMLS Beta } & \multicolumn{6}{|c|}{ WMLS Beta } \\
\hline $\mathrm{S}$ & -0.58 & -0.36 & -0.13 & 0.15 & 0.49 & 1.07 & -0.63 & -0.19 & 0.03 & 0.20 & 0.50 & 1.13 \\
\hline 2 & -0.55 & -0.32 & 0.02 & 0.33 & 0.58 & 1.14 & -0.70 & -0.25 & -0.04 & 0.19 & 0.51 & 1.21 \\
\hline 3 & -0.49 & -0.20 & 0.16 & 0.32 & 0.50 & 0.99 & -0.56 & -0.25 & -0.09 & 0.08 & 0.44 & 1.00 \\
\hline 4 & -0.44 & 0.10 & 0.25 & 0.31 & 0.31 & 0.74 & -0.38 & -0.18 & -0.06 & 0.06 & 0.32 & 0.71 \\
\hline B & -0.02 & 0.06 & -0.00 & -0.01 & -0.19 & -0.17 & 0.03 & 0.09 & 0.08 & 0.02 & -0.07 & -0.09 \\
\hline \multirow[t]{2}{*}{ S-B } & -0.56 & -0.42 & -0.13 & 0.16 & 0.68 & & -0.66 & -0.29 & -0.06 & 0.18 & 0.56 & \\
\hline & \multicolumn{6}{|c|}{ HMLB Betas } & \multicolumn{6}{|c|}{ WMLB Betas } \\
\hline $\mathrm{S}$ & 0.09 & 0.12 & 0.12 & 0.10 & 0.01 & -0.09 & -0.01 & 0.01 & -0.03 & -0.05 & -0.11 & -0.10 \\
\hline 2 & 0.05 & 0.16 & 0.08 & 0.12 & 0.08 & 0.03 & -0.04 & 0.01 & 0.02 & -0.01 & -0.04 & -0.01 \\
\hline 3 & -0.09 & 0.04 & 0.12 & 0.18 & 0.19 & 0.28 & -0.13 & -0.03 & 0.05 & 0.07 & 0.08 & 0.21 \\
\hline 4 & -0.14 & -0.02 & 0.06 & 0.18 & 0.39 & 0.52 & -0.33 & -0.10 & 0.01 & 0.13 & 0.22 & 0.55 \\
\hline B & -0.55 & -0.11 & 0.19 & 0.38 & 0.72 & 1.28 & -0.67 & -0.33 & -0.05 & 0.25 & 0.65 & 1.31 \\
\hline S-B & 0.65 & 0.24 & -0.07 & -0.28 & -0.72 & & 0.66 & 0.34 & 0.02 & -0.30 & -0.75 & \\
\hline
\end{tabular}


Table 5: Baseline Cross-Sectional Asset Pricing Tests for Global Value Portfolios The table reports the second-stage Fama-MacBeth (1973) regression coefficients in \% p.a. with 25 global portfolios formed on size and BE/ME using OLS and GLS estimation. Shanken (1992) corrected t-statistics are in parentheses. $\bar{R}_{\text {OLS }}^{2}$ is the cross-sectional adjusted OLS $R^{2} ; \rho_{G L S}^{2}$ is the cross-sectional GLS $R^{2}$. Mean squared pricing errors (MSPE) and mean absolute pricing errors (MAPE) are in \% p.a. The sample period is November 1990 - July 2013.

\begin{tabular}{|c|c|c|c|c|}
\hline & (A) & (B) & (C) & (D) \\
\hline \multicolumn{5}{|c|}{ OLS Estimation } \\
\hline$\lambda_{M}$ & $\begin{array}{c}6.21 \\
(1.89)\end{array}$ & $\begin{array}{c}4.88 \\
(1.53)\end{array}$ & $\begin{array}{c}5.76 \\
(1.81)\end{array}$ & $\begin{array}{c}5.30 \\
(1.67)\end{array}$ \\
\hline$\lambda_{\text {SMB }}$ & & $\begin{array}{c}1.43 \\
(0.92)\end{array}$ & $\begin{array}{c}0.94 \\
(0.61)\end{array}$ & $\begin{array}{c}1.52 \\
(0.98)\end{array}$ \\
\hline$\lambda_{H M L}$ & & $\begin{array}{c}5.09 \\
(2.89)\end{array}$ & $\begin{array}{c}5.35 \\
(3.01)\end{array}$ & \\
\hline$\lambda_{\text {WML }}$ & & & $\begin{array}{l}23.72 \\
(3.07)\end{array}$ & \\
\hline$\lambda_{\text {HMLS }}$ & & & & $\begin{array}{c}5.96 \\
(3.02)\end{array}$ \\
\hline$\lambda_{\text {HMLB }}$ & & & & $\begin{array}{c}2.08 \\
(1.05)\end{array}$ \\
\hline $\bar{R}_{O L S}^{2}$ & -0.39 & 0.45 & 0.54 & 0.69 \\
\hline MSPE & 0.67 & 0.24 & 0.19 & 0.13 \\
\hline MAPE & 2.19 & 1.19 & 1.04 & 1.03 \\
\hline \multicolumn{5}{|c|}{ GLS Estimation } \\
\hline$\lambda_{M}$ & $\begin{array}{c}5.62 \\
(1.77)\end{array}$ & $\begin{array}{c}5.62 \\
(1.77)\end{array}$ & $\begin{array}{c}5.85 \\
(1.84)\end{array}$ & $\begin{array}{c}5.66 \\
(1.78)\end{array}$ \\
\hline$\lambda_{\text {SMB }}$ & & $\begin{array}{c}1.07 \\
(0.70)\end{array}$ & $\begin{array}{c}1.00 \\
(0.66)\end{array}$ & $\begin{array}{c}1.05 \\
(0.69)\end{array}$ \\
\hline$\lambda_{\text {нмL }}$ & & $\begin{array}{c}4.93 \\
(2.85)\end{array}$ & $\begin{array}{c}4.99 \\
(2.89)\end{array}$ & \\
\hline$\lambda_{\text {WML }}$ & & & $\begin{array}{l}13.31 \\
(2.21)\end{array}$ & \\
\hline$\lambda_{\text {HMLS }}$ & & & & $\begin{array}{c}7.30 \\
(3.79)\end{array}$ \\
\hline$\lambda_{\text {HMLB }}$ & & & & $\begin{array}{c}2.47 \\
(1.27)\end{array}$ \\
\hline$\rho_{G L S}^{2}$ & -0.34 & -0.21 & -0.11 & 0.17 \\
\hline $\begin{array}{l}\text { MSPE } \\
\text { MAPE }\end{array}$ & $\begin{array}{l}0.70 \\
2.22\end{array}$ & $\begin{array}{l}0.27 \\
1.39\end{array}$ & $\begin{array}{l}0.21 \\
1.14\end{array}$ & $\begin{array}{l}0.16 \\
1.18\end{array}$ \\
\hline
\end{tabular}


Table 6: Baseline Cross-Sectional Asset Pricing Tests for Global Momentum Portfolios The table reports the second-stage Fama-MacBeth (1973) regression coefficients in \% p.a. with 25 global portfolios formed on size and momentum using OLS and GLS estimation. Shanken (1992) corrected $t$-statistics are in parentheses. $\bar{R}_{O L S}^{2}$ is the crosssectional adjusted OLS $R^{2} ; \rho_{G L S}^{2}$ is the cross-sectional GLS $R^{2}$. Mean squared pricing errors (MSPE) and mean absolute pricing errors (MAPE) are in \% p.a. The sample period is November 1990 - July 2013.

\begin{tabular}{|c|c|c|c|c|}
\hline & (A) & (B) & (C) & (D) \\
\hline \multicolumn{5}{|c|}{ OLS Estimation } \\
\hline \multirow[t]{2}{*}{$\lambda_{M}$} & 6.69 & 4.80 & 5.14 & 4.93 \\
\hline & $(2.04)$ & $(1.51)$ & $(1.62)$ & $(1.55)$ \\
\hline \multirow[t]{2}{*}{$\lambda_{S M B}$} & & 5.55 & 3.07 & 3.41 \\
\hline & & (3.24) & $(1.92)$ & $(2.12)$ \\
\hline \multirow[t]{2}{*}{$\lambda_{H M L}$} & & -5.20 & 4.45 & 4.99 \\
\hline & & $(-1.57)$ & $(1.76)$ & (1.93) \\
\hline \multirow[t]{2}{*}{$\lambda_{W M L}$} & & & 7.88 & \\
\hline & & & $(2.65)$ & \\
\hline \multirow[t]{2}{*}{$\lambda_{W M L S}$} & & & & 10.18 \\
\hline & & & & (3.53) \\
\hline \multirow[t]{2}{*}{$\lambda_{W M L B}$} & & & & 3.56 \\
\hline & & & & $(1.07)$ \\
\hline $\bar{R}_{O L S}^{2}$ & -0.40 & 0.03 & 0.66 & 0.84 \\
\hline MSPE & 1.72 & 1.10 & 0.37 & 0.17 \\
\hline MAPE & 3.46 & 2.79 & 1.53 & 1.06 \\
\hline \multicolumn{5}{|c|}{ GLS Estimation } \\
\hline \multirow[t]{2}{*}{$\lambda_{M}$} & 5.58 & 5.47 & 5.40 & 5.40 \\
\hline & $(1.76)$ & $(1.72)$ & $(1.70)$ & $(1.70)$ \\
\hline \multirow[t]{2}{*}{$\lambda_{S M B}$} & & 2.54 & 2.38 & 2.41 \\
\hline & & $(1.62)$ & $(1.52)$ & $(1.54)$ \\
\hline \multirow[t]{2}{*}{$\lambda_{H M L}$} & & 2.30 & 3.83 & 3.99 \\
\hline & & $(0.99)$ & $(1.60)$ & $(1.64)$ \\
\hline \multirow[t]{2}{*}{$\lambda_{W M L}$} & & & 7.67 & \\
\hline & & & (2.59) & \\
\hline \multirow[t]{2}{*}{$\lambda_{W M L S}$} & & & & 10.54 \\
\hline & & & & $(3.67)$ \\
\hline \multirow[t]{2}{*}{$\lambda_{W M L B}$} & & & & 4.74 \\
\hline & & & & $(1.43)$ \\
\hline$\rho_{G L S}^{2}$ & -0.05 & -0.01 & 0.08 & 0.24 \\
\hline MSPE & 1.83 & 1.60 & 0.38 & 0.20 \\
\hline MAPE & 3.69 & 3.29 & 1.50 & 1.11 \\
\hline
\end{tabular}


Table 7: Baseline Cross-Sectional Asset Pricing Tests for Global Value and Momentum Portfolios Jointly

The table reports the second-stage Fama-MacBeth (1973) regression coefficients in \% p.a. with 25 global portfolios formed on size and BE/ME and 25 global portfolios formed on size and momentum jointly using OLS and GLS estimation. Shanken (1992) corrected $t$-statistics are in parentheses. $\bar{R}_{O L S}^{2}$ is the cross-sectional adjusted OLS $R^{2} ; \rho_{G L S}^{2}$ is the cross-sectional GLS $R^{2}$. Mean squared pricing errors (MSPE) and mean absolute pricing errors (MAPE) are in \% p.a. The sample period is November 1990 - July 2013.

\begin{tabular}{|c|c|c|c|c|}
\hline & (A) & (B) & (C) & (D) \\
\hline \multicolumn{5}{|c|}{ OLS Estimation } \\
\hline \multirow[t]{2}{*}{$\lambda_{M}$} & 6.45 & 4.37 & 5.20 & 5.36 \\
\hline & (1.97) & (1.37) & (1.63) & $(1.68)$ \\
\hline \multirow[t]{2}{*}{$\lambda_{S M B}$} & & 3.18 & 1.96 & 2.05 \\
\hline & & (2.02) & (1.26) & (1.32) \\
\hline \multirow[t]{2}{*}{$\lambda_{\text {HML }}$} & & 2.42 & 5.37 & \\
\hline & & (1.25) & (2.94) & \\
\hline \multirow[t]{2}{*}{$\lambda_{W M L}$} & & & 7.83 & \\
\hline & & & (2.63) & \\
\hline \multirow[t]{2}{*}{$\lambda_{\text {HMLS }}$} & & & & 6.34 \\
\hline & & & & (3.11) \\
\hline \multirow[t]{2}{*}{$\lambda_{\text {HMLB }}$} & & & & 1.84 \\
\hline & & & & (0.93) \\
\hline \multirow[t]{2}{*}{$\lambda_{\text {WMLS }}$} & & & & 10.09 \\
\hline & & & & (3.49) \\
\hline \multirow[t]{2}{*}{$\lambda_{\text {WMLB }}$} & & & & 3.20 \\
\hline & & & & (0.96) \\
\hline $\bar{R}_{O L S}^{2}$ & -0.38 & -0.17 & 0.61 & 0.81 \\
\hline MSPE & 1.20 & 0.97 & 0.32 & 0.15 \\
\hline MAPE & 2.84 & 2.44 & 1.37 & 1.00 \\
\hline
\end{tabular}


Table 7: Continued

\begin{tabular}{ccccc}
\hline & $(\mathrm{A})$ & $(\mathrm{B})$ & $(\mathrm{C})$ & $(\mathrm{D})$ \\
\hline & & GLS Estimation & & \\
\hline$\lambda_{M}$ & 5.67 & 5.67 & 5.67 & 5.70 \\
& $(1.79)$ & $(1.79)$ & $(1.79)$ & $(1.80)$ \\
$\lambda_{\text {SMB }}$ & & 1.09 & 1.08 & 1.07 \\
& & $(0.72)$ & $(0.71)$ & $(0.71)$ \\
$\lambda_{\text {HML }}$ & & 4.82 & 4.84 & \\
& & $(2.79)$ & $(2.80)$ & \\
$\lambda_{\text {WML }}$ & & 7.71 & \\
& & & $(2.61)$ & \\
$\lambda_{\text {HMLS }}$ & & & & 7.33 \\
& & & & $(3.81)$ \\
$\lambda_{\text {HMLB }}$ & & & & 2.26 \\
$\lambda_{\text {WMLS }}$ & & & & $1.16)$ \\
$\lambda_{\text {WMLB }}$ & & & & $(3.69)$ \\
$\rho_{\text {GLS }}^{2}$ & & & 0.08 & $(1.43)$ \\
$M S P E$ & -0.03 & 0.02 & 0.33 & 0.27 \\
$M A P E$ & 1.25 & 1.15 & 1.35 & 0.18 \\
\hline \hline
\end{tabular}


Table 8: Time Series Asset Pricing Tests for Regional Value Portfolios and Regional or Global Factors

The table reports a summary of the first-stage Fama-MacBeth (1973) regressions using 25 regional portfolios formed on size and BE/ME and regional or global factors. The tested models are (A) CAPM; (B) three-factor Fama-French (1993); (C) four-factor Carhart (1997); (D) modified Fama-French model. The GRS statistic tests whether all intercepts in a set of 25 regressions are zero; $\mathrm{p}$-val. is the associated p-value; $|\alpha|$ is the average absolute intercept; s( $\alpha)$ is the average standard error of the intercepts; $\operatorname{SR}(\alpha)$ is the Sharpe ratio for the intercepts; and $\bar{R}_{\text {OLS }}^{2}$ is the average OLS $R^{2}$ adjusted for the degrees of freedom. With 25 portfolios and 273 monthly returns, critical values of the GRS statistic for all models are 90\%: 1.41; 95\%: 1.55; 99\%: 1.85 . The sample period is November 1990 - July 2013.

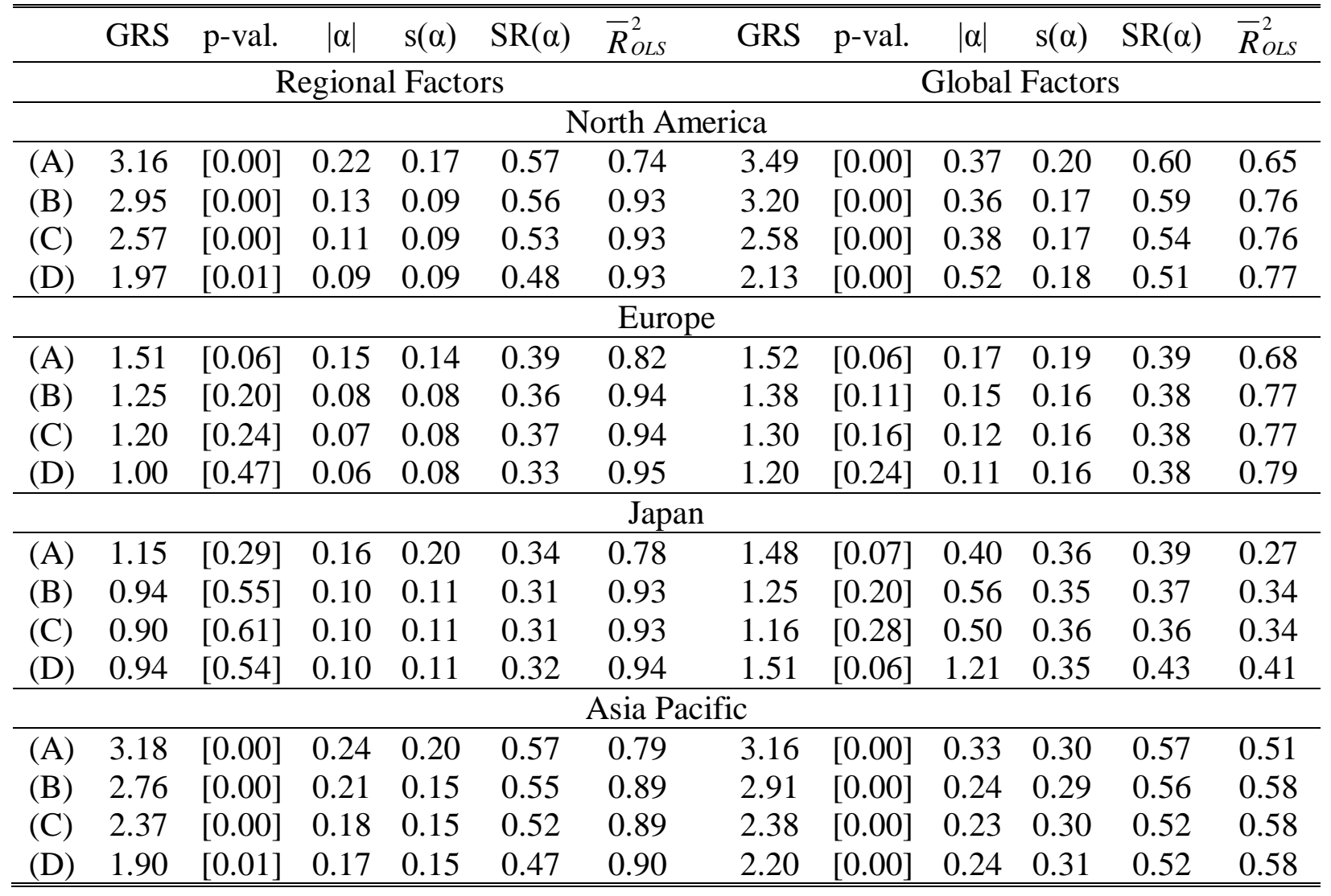


Table 9: Time Series Asset Pricing Tests for Regional Momentum Portfolios and Regional or Global Factors

The table reports a summary of the first-stage Fama-MacBeth (1973) regressions using 25 regional portfolios formed on size and momentum and regional or global factors. The tested models are (A) CAPM; (B) three-factor Fama-French (1993); (C) four-factor Carhart (1997); (D) modified Carhart model. The GRS statistic tests whether all intercepts in a set of 25 regressions are zero; p-val. is the associated p-value; $|\alpha|$ is the average absolute intercept; $s(\alpha)$ is the average standard error of the intercepts; $\operatorname{SR}(\alpha)$ is the Sharpe ratio for the intercepts; and $\bar{R}_{O L S}^{2}$ is the average OLS $R^{2}$ adjusted for the degrees of freedom. With 25 portfolios and 273 monthly returns, critical values of the GRS statistic for all models are 90\%: 1.41; 95\%: 1.55; 99\%: 1.85. The sample period is November 1990 - July 2013.

\begin{tabular}{|c|c|c|c|c|c|c|c|c|c|c|c|c|}
\hline & GRS & p-val. & $|\alpha|$ & $s(\alpha)$ & $\operatorname{SR}(\alpha)$ & $\bar{R}_{O L S}^{2}$ & GRS & p-val. & $|\alpha|$ & $s(\alpha)$ & $\operatorname{SR}(\alpha)$ & $\bar{R}_{O L S}^{2}$ \\
\hline & \multicolumn{6}{|c|}{ Regional Factors } & \multicolumn{6}{|c|}{ Global Factors } \\
\hline \multicolumn{13}{|c|}{ North America } \\
\hline (A) & 3.81 & {$[0.00]$} & 0.37 & 0.19 & 0.63 & 0.71 & 4.07 & {$[0.00]$} & 0.49 & 0.21 & 0.65 & 0.61 \\
\hline (B) & 3.67 & {$[0.00]$} & 0.32 & 0.14 & 0.63 & 0.83 & 3.64 & {$[0.00]$} & 0.48 & 0.20 & 0.62 & 0.68 \\
\hline (C) & 3.28 & {$[0.00]$} & 0.14 & 0.10 & 0.60 & 0.92 & 3.14 & {$[0.00]$} & 0.46 & 0.17 & 0.60 & 0.76 \\
\hline (D) & 2.96 & {$[0.00]$} & 0.14 & 0.09 & 0.58 & 0.93 & 2.82 & {$[0.00]$} & 0.44 & 0.18 & 0.58 & 0.76 \\
\hline \multicolumn{13}{|c|}{ Europe } \\
\hline (A) & 4.66 & {$[0.00]$} & 0.40 & 0.16 & 0.69 & 0.79 & 4.69 & {$[0.00]$} & 0.41 & 0.20 & 0.69 & 0.65 \\
\hline (B) & 4.95 & {$[0.00]$} & 0.43 & 0.12 & 0.72 & 0.87 & 4.29 & {$[0.00]$} & 0.44 & 0.18 & 0.68 & 0.72 \\
\hline (C) & 3.63 & {$[0.00]$} & 0.18 & 0.09 & 0.65 & 0.93 & 3.53 & {$[0.00]$} & 0.21 & 0.17 & 0.63 & 0.76 \\
\hline (D) & 1.99 & {$[0.00]$} & 0.13 & 0.09 & 0.52 & 0.94 & 2.81 & {$[0.00]$} & 0.19 & 0.17 & 0.58 & 0.77 \\
\hline \multicolumn{13}{|c|}{ Japan } \\
\hline (A) & 0.79 & {$[0.75]$} & 0.11 & 0.21 & 0.28 & 0.75 & 1.00 & {$[0.47]$} & 0.35 & 0.35 & 0.32 & 0.26 \\
\hline (B) & 0.88 & [0.63] & 0.15 & 0.15 & 0.30 & 0.87 & 1.02 & {$[0.45]$} & 0.52 & 0.34 & 0.33 & 0.33 \\
\hline (C) & 0.90 & [0.61] & 0.09 & 0.11 & 0.31 & 0.92 & 1.20 & {$[0.24]$} & 0.45 & 0.35 & 0.37 & 0.34 \\
\hline (D) & 0.89 & [0.62] & 0.10 & 0.11 & 0.31 & 0.93 & 1.30 & {$[0.16]$} & 0.36 & 0.36 & 0.40 & 0.35 \\
\hline \multicolumn{13}{|c|}{ Asia Pacific } \\
\hline (A) & 4.69 & {$[0.00]$} & 0.38 & 0.21 & 0.70 & 0.76 & 4.26 & {$[0.00]$} & 0.51 & 0.31 & 0.66 & 0.49 \\
\hline (B) & 4.83 & {$[0.00]$} & 0.49 & 0.17 & 0.72 & 0.85 & 4.26 & {$[0.00]$} & 0.45 & 0.30 & 0.68 & 0.55 \\
\hline (C) & 3.82 & {$[0.00]$} & 0.28 & 0.15 & 0.67 & 0.89 & 3.54 & {$[0.00]$} & 0.34 & 0.30 & 0.63 & 0.57 \\
\hline (D) & 3.15 & {$[0.00]$} & 0.26 & 0.15 & 0.62 & 0.90 & 3.18 & {$[0.00]$} & 0.29 & 0.31 & 0.62 & 0.57 \\
\hline
\end{tabular}


Table 10: Summary of Cross-Sectional Asset Pricing Tests for Regional Value and Momentum Portfolios with Regional and Global Factors

For details see notes to Tables 5 and 6 .

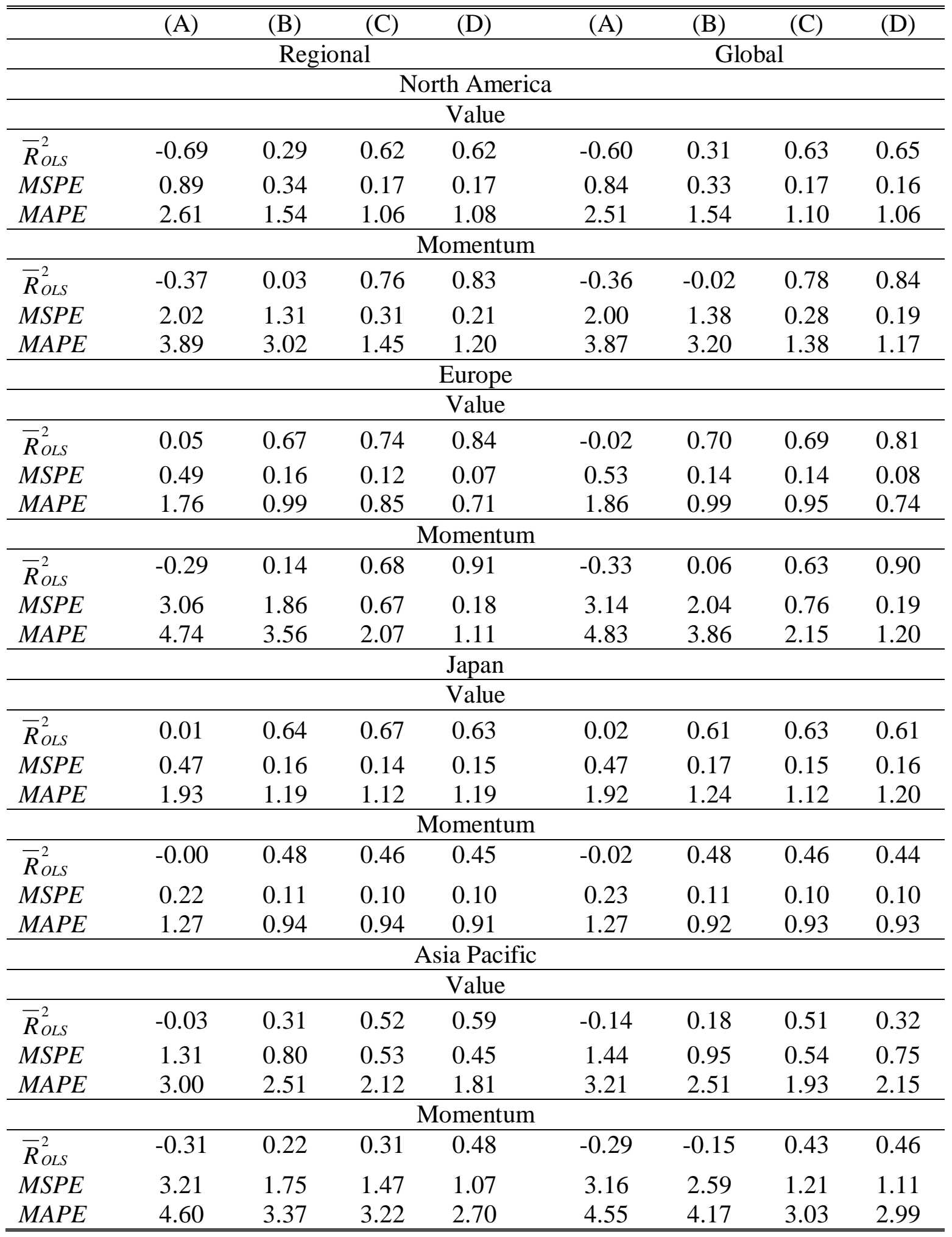


Table 11: Global versus Regional Pricing Factors and Regional Value Portfolios

The table reports the second-stage Fama-MacBeth (1973) regression coefficients in \% p.a. with (i) 25 regional portfolios formed on size and BE/ME and (ii) 25 regional portfolios formed on size and momentum using OLS estimation. Shanken (1992) corrected $t$-statistics are in parentheses. The tested models are (i) the regional and global versions of the modified Fama-French model and (ii) the regional and global versions of the modified Carhart model. $\bar{R}_{\text {oLs }}^{2}$ is the cross-sectional adjusted OLS $R^{2}$. Mean squared pricing errors (MSPE) and mean absolute pricing errors (MAPE) are in \% p.a. The sample period is November 1990 - July 2013.

\begin{tabular}{|c|c|c|c|c|c|c|c|c|}
\hline \multirow{2}{*}{$\begin{array}{l}\text { Returns } \\
\text { Factors } \\
\end{array}$} & \multicolumn{2}{|c|}{ North America } & \multicolumn{2}{|c|}{ Europe } & \multicolumn{2}{|c|}{ Japan } & \multicolumn{2}{|c|}{ Asia Pacific } \\
\hline & local & global & local & global & local & global & local & global \\
\hline \multicolumn{9}{|c|}{ Value } \\
\hline$\lambda_{M}$ & $\begin{array}{c}8.52 \\
(2.67)\end{array}$ & $\begin{array}{l}11.10 \\
(3.06)\end{array}$ & $\begin{array}{c}6.78 \\
(1.85)\end{array}$ & $\begin{array}{c}7.28 \\
(2.04)\end{array}$ & $\begin{array}{c}-1.00 \\
(-0.24)\end{array}$ & $\begin{array}{c}-2.29 \\
(-0.47)\end{array}$ & $\begin{array}{c}9.82 \\
(2.19)\end{array}$ & $\begin{array}{c}5.56 \\
(1.24)\end{array}$ \\
\hline$\lambda_{S M B}$ & $\begin{array}{c}2.43 \\
(1.04)\end{array}$ & $\begin{array}{c}3.21 \\
(1.63)\end{array}$ & $\begin{array}{c}-1.01 \\
(-0.60)\end{array}$ & $\begin{array}{c}-0.54 \\
(-0.25)\end{array}$ & $\begin{array}{c}-0.44 \\
(-0.18)\end{array}$ & $\begin{array}{c}-2.82 \\
(-0.82)\end{array}$ & $\begin{array}{c}-2.02 \\
(-0.89)\end{array}$ & $\begin{array}{c}-2.97 \\
(-0.73)\end{array}$ \\
\hline$\lambda_{\text {HMLS }}$ & $\begin{array}{c}6.07 \\
(1.98)\end{array}$ & $\begin{array}{c}6.48 \\
(2.75)\end{array}$ & $\begin{array}{c}6.20 \\
(2.99)\end{array}$ & $\begin{array}{c}4.92 \\
(2.20)\end{array}$ & $\begin{array}{c}4.21 \\
(1.83)\end{array}$ & $\begin{array}{c}7.92 \\
(2.42)\end{array}$ & $\begin{array}{l}10.43 \\
(4.16)\end{array}$ & $\begin{array}{l}12.47 \\
(2.59)\end{array}$ \\
\hline$\lambda_{\text {HMLB }}$ & $\begin{array}{c}0.09 \\
(0.04)\end{array}$ & $\begin{array}{c}1.43 \\
(0.62)\end{array}$ & $\begin{array}{c}2.24 \\
(0.99)\end{array}$ & $\begin{array}{c}1.55 \\
(0.58)\end{array}$ & $\begin{array}{c}6.77 \\
(2.29)\end{array}$ & $\begin{array}{c}4.61 \\
(1.12)\end{array}$ & $\begin{array}{c}1.69 \\
(0.52)\end{array}$ & $\begin{array}{c}0.45 \\
(0.08)\end{array}$ \\
\hline $\bar{R}_{O L S}^{2}$ & 0.62 & 0.65 & 0.84 & 0.81 & 0.63 & 0.61 & 0.59 & 0.32 \\
\hline MSPE & 0.17 & 0.16 & 0.07 & 0.08 & 0.15 & 0.16 & 0.45 & 0.75 \\
\hline MAPE & 1.08 & 1.06 & 0.71 & 0.74 & 1.19 & 1.20 & 1.81 & 2.15 \\
\hline \multicolumn{9}{|c|}{ Momentum } \\
\hline$\lambda_{M}$ & $\begin{array}{c}7.58 \\
(2.37)\end{array}$ & $\begin{array}{l}10.13 \\
(2.84)\end{array}$ & $\begin{array}{c}6.59 \\
(1.79)\end{array}$ & $\begin{array}{c}3.99 \\
(1.08)\end{array}$ & $\begin{array}{l}-1.11 \\
(-0.26)\end{array}$ & $\begin{array}{c}-2.72 \\
(-0.56)\end{array}$ & $\begin{array}{l}10.35 \\
(2.30)\end{array}$ & $\begin{array}{c}6.78 \\
(1.38)\end{array}$ \\
\hline$\lambda_{S M B}$ & $\begin{array}{c}4.13 \\
(1.71)\end{array}$ & $\begin{array}{c}2.58 \\
(1.31)\end{array}$ & $\begin{array}{c}0.89 \\
(0.50)\end{array}$ & $\begin{array}{c}3.81 \\
(1.37)\end{array}$ & $\begin{array}{c}2.95 \\
(1.01)\end{array}$ & $\begin{array}{c}3.09 \\
(1.07)\end{array}$ & $\begin{array}{c}0.57 \\
(0.23)\end{array}$ & $\begin{array}{c}-2.40 \\
(-0.58)\end{array}$ \\
\hline$\lambda_{\text {HML }}$ & $\begin{array}{c}8.72 \\
(2.57)\end{array}$ & $\begin{array}{c}6.63 \\
(2.60)\end{array}$ & $\begin{array}{c}6.80 \\
(1.69)\end{array}$ & $\begin{array}{c}4.86 \\
(1.25)\end{array}$ & $\begin{array}{c}-0.83 \\
(-0.15)\end{array}$ & $\begin{array}{c}-0.06 \\
(-0.01)\end{array}$ & $\begin{array}{c}-2.97 \\
(-0.48)\end{array}$ & $\begin{array}{c}8.17 \\
(1.63)\end{array}$ \\
\hline$\lambda_{\text {WMLS }}$ & $\begin{array}{c}9.71 \\
(2.60)\end{array}$ & $\begin{array}{c}8.36 \\
(2.46)\end{array}$ & $\begin{array}{l}15.81 \\
(5.54)\end{array}$ & $\begin{array}{l}23.90 \\
(5.56)\end{array}$ & $\begin{array}{c}0.25 \\
(0.08)\end{array}$ & $\begin{array}{c}1.70 \\
(0.38)\end{array}$ & $\begin{array}{l}14.28 \\
(4.38)\end{array}$ & $\begin{array}{l}23.45 \\
(3.52)\end{array}$ \\
\hline$\lambda_{\text {WMLB }}$ & $\begin{array}{c}4.63 \\
(1.17)\end{array}$ & $\begin{array}{c}3.26 \\
(0.89)\end{array}$ & $\begin{array}{c}4.98 \\
(1.36)\end{array}$ & $\begin{array}{c}4.97 \\
(1.15)\end{array}$ & $\begin{array}{c}1.73 \\
(0.41)\end{array}$ & $\begin{array}{c}3.52 \\
(0.55)\end{array}$ & $\begin{array}{c}3.63 \\
(0.82)\end{array}$ & $\begin{array}{c}15.38 \\
(1.90)\end{array}$ \\
\hline $\bar{R}_{O L S}^{2}$ & 0.83 & 0.84 & 0.91 & 0.90 & 0.45 & 0.44 & 0.48 & 0.46 \\
\hline MSPE & 0.21 & 0.19 & 0.18 & 0.19 & 0.10 & 0.10 & 1.07 & 1.11 \\
\hline MAPE & 1.20 & 1.17 & 1.11 & 1.20 & 0.91 & 0.93 & 2.70 & 2.99 \\
\hline
\end{tabular}


Table 12: Funding Liquidity Betas of Value Portfolios

The table shows the estimated liquidity betas of 25 global and regional portfolios formed on size and BE/ME. Funding liquidity is measured by the global TED spread. Estimates significant at the $5 \%$ level are highlighted in bold face. The sample period is November 1990 - July 2013.

\begin{tabular}{|c|c|c|c|c|c|c|}
\hline & G & 2 & 3 & 4 & $\mathrm{~V}$ & V-G \\
\hline \multicolumn{7}{|c|}{ Global } \\
\hline S & 1.08 & 0.46 & 0.37 & 0.03 & -0.11 & -1.20 \\
\hline 2 & 0.34 & 0.19 & 0.12 & -0.17 & 0.03 & -0.31 \\
\hline 3 & -0.46 & -0.19 & -0.29 & -0.61 & -0.18 & 0.28 \\
\hline 4 & -0.53 & -0.36 & -0.45 & -0.32 & -0.37 & 0.16 \\
\hline B & 0.13 & 0.06 & 0.32 & 0.06 & 0.29 & 0.16 \\
\hline S-B & 0.95 & 0.40 & 0.06 & -0.03 & -0.40 & \\
\hline \multicolumn{7}{|c|}{ North America } \\
\hline S & 0.38 & 0.16 & $\begin{array}{l}-0.04 \\
\end{array}$ & -0.16 & -0.27 & -0.65 \\
\hline 2 & 0.13 & 0.01 & -0.06 & 0.11 & 0.12 & -0.01 \\
\hline 3 & -0.06 & 0.05 & 0.13 & -0.46 & 0.40 & 0.46 \\
\hline 4 & 0.01 & -0.56 & -0.55 & -0.09 & -0.03 & -0.04 \\
\hline B & 0.17 & 0.01 & -0.15 & -0.25 & 0.84 & 0.67 \\
\hline S-B & 0.22 & 0.15 & 0.11 & 0.09 & -1.10 & \\
\hline \multicolumn{7}{|c|}{ Europe } \\
\hline$S$ & 1.28 & 0.74 & 0.29 & -0.37 & -0.82 & -2.10 \\
\hline 2 & 1.11 & 0.23 & -0.20 & -0.67 & -0.69 & -1.80 \\
\hline 3 & 0.25 & 0.07 & -0.21 & -0.83 & -0.26 & -0.51 \\
\hline 4 & -0.05 & -0.25 & -0.57 & -0.49 & -0.41 & -0.36 \\
\hline B & -0.18 & 0.04 & 0.35 & -0.10 & -0.00 & 0.18 \\
\hline S-B & 1.46 & 0.71 & -0.06 & -0.28 & -0.82 & \\
\hline \multicolumn{7}{|c|}{ Japan } \\
\hline S & 0.08 & 0.30 & -0.20 & 0.04 & -0.30 & -0.38 \\
\hline 2 & 0.02 & -0.15 & 0.37 & -0.17 & 0.03 & 0.00 \\
\hline 3 & 0.18 & -0.15 & 0.07 & -0.17 & 0.16 & -0.02 \\
\hline 4 & -0.55 & -0.42 & 0.00 & -0.31 & 0.34 & 0.90 \\
\hline B & -0.27 & 0.11 & -0.01 & 0.41 & -0.22 & 0.05 \\
\hline S-B & 0.35 & 0.19 & -0.19 & -0.38 & -0.08 & \\
\hline \multicolumn{7}{|c|}{ Asia Pacific } \\
\hline$S$ & 0.52 & -0.20 & 0.73 & 0.39 & -0.41 & -0.93 \\
\hline 2 & 0.50 & 0.64 & 0.34 & 0.39 & -0.65 & -1.14 \\
\hline 3 & 0.37 & 0.12 & -1.54 & -0.86 & -0.42 & -0.79 \\
\hline 4 & -0.85 & -0.54 & -1.02 & -0.75 & -0.45 & 0.39 \\
\hline B & -0.21 & -0.11 & 0.28 & 0.75 & -0.39 & -0.17 \\
\hline S-B & 0.74 & -0.09 & 0.45 & -0.36 & -0.02 & \\
\hline
\end{tabular}


Table 13: Funding Liquidity Betas of Momentum Portfolios

The table shows the estimated liquidity betas of 25 global and regional portfolios formed on size and momentum. Funding liquidity is measured by the global TED spread. Estimates significant at the 5\% level are highlighted in bold face. The sample period is November 1990 - July 2013.

\begin{tabular}{|c|c|c|c|c|c|c|}
\hline & G & 2 & 3 & 4 & $\mathrm{~V}$ & $\mathrm{~V}-\mathrm{G}$ \\
\hline \multicolumn{7}{|c|}{ Global } \\
\hline S & 0.54 & -0.05 & -0.56 & -0.49 & -0.06 & -0.60 \\
\hline 2 & 0.41 & -0.07 & -0.26 & -0.71 & -0.44 & -0.86 \\
\hline 3 & 0.01 & -0.02 & -0.71 & -0.67 & -0.69 & -0.70 \\
\hline 4 & 0.23 & -0.31 & -0.40 & -0.39 & -0.77 & -1.00 \\
\hline B & -0.13 & 0.14 & 0.21 & 0.03 & 0.38 & 0.51 \\
\hline S-B & 0.67 & -0.19 & -0.77 & -0.52 & -0.44 & \\
\hline \multicolumn{7}{|c|}{ North America } \\
\hline $\mathrm{S}$ & -0.84 & -0.64 & -0.35 & -0.25 & 0.05 & 0.89 \\
\hline 2 & -0.53 & -0.02 & -0.01 & 0.16 & 0.21 & 0.73 \\
\hline 3 & -0.14 & 0.04 & -0.31 & 0.20 & 0.50 & 0.64 \\
\hline 4 & -0.02 & -0.17 & -0.14 & -0.42 & -0.34 & -0.32 \\
\hline B & -0.02 & 0.12 & 0.45 & 0.09 & 0.07 & 0.09 \\
\hline S-B & -0.82 & -0.76 & -0.80 & -0.34 & -0.02 & \\
\hline \multicolumn{7}{|c|}{ Europe } \\
\hline $\mathrm{S}$ & 0.63 & -0.08 & -0.76 & -0.50 & 0.35 & -0.29 \\
\hline 2 & 0.78 & -0.30 & -0.19 & -0.50 & 0.24 & -0.55 \\
\hline 3 & 0.58 & -0.39 & -0.68 & -0.31 & 0.13 & -0.46 \\
\hline 4 & 0.54 & -0.28 & -0.06 & -0.40 & -0.32 & -0.86 \\
\hline B & -0.24 & 0.03 & 0.33 & -0.10 & 0.44 & 0.68 \\
\hline S-B & 0.87 & -0.11 & -1.09 & -0.40 & -0.10 & \\
\hline \multicolumn{7}{|c|}{ Japan } \\
\hline S & 0.28 & 0.15 & -0.25 & -0.72 & -0.82 & -1.10 \\
\hline 2 & 0.10 & 0.73 & 0.18 & -0.23 & -0.21 & -0.30 \\
\hline 3 & -0.35 & -0.04 & 0.05 & -0.23 & -0.52 & -0.17 \\
\hline 4 & -0.81 & -0.34 & -0.24 & -0.10 & -0.17 & 0.64 \\
\hline B & 0.33 & -0.50 & -0.62 & 0.01 & 0.29 & -0.04 \\
\hline S-B & -0.05 & 0.65 & 0.36 & -0.73 & -1.11 & \\
\hline \multicolumn{7}{|c|}{ Asia Pacific } \\
\hline $\mathrm{S}$ & 1.22 & -0.39 & -0.63 & -0.04 & 0.50 & -0.71 \\
\hline 2 & 1.59 & -0.08 & -0.70 & -0.67 & -0.42 & -2.02 \\
\hline 3 & 0.13 & -0.51 & -1.34 & -0.73 & -0.33 & -0.46 \\
\hline 4 & -0.56 & -0.54 & -1.45 & -1.03 & 0.28 & 0.84 \\
\hline B & 0.27 & 0.08 & -0.28 & -0.24 & 1.14 & 0.87 \\
\hline S-B & 0.95 & -0.47 & -0.35 & 0.20 & -0.64 & \\
\hline
\end{tabular}


Table 14: Asset Pricing Tests with Funding Liquidity Risk

Funding liquidity is proxied by the global or U.S. TED spreads. Test assets are 25 portfolios formed on size and BE/ME and 25 portfolios formed on size and momentum jointly. For further details see notes to Table 7. The sample period is November 1990 July 2013.

\begin{tabular}{|c|c|c|c|c|c|}
\hline & Global & North America & Europe & Japan & Asia Pacific \\
\hline \multicolumn{6}{|c|}{ Global Funding Liquidity Measures } \\
\hline$\lambda_{M}$ & $\begin{array}{c}4.98 \\
(1.57)\end{array}$ & $\begin{array}{c}8.05 \\
(2.52)\end{array}$ & $\begin{array}{c}6.76 \\
(1.84)\end{array}$ & $\begin{array}{c}-1.39 \\
(-0.33)\end{array}$ & $\begin{array}{c}8.98 \\
(2.00)\end{array}$ \\
\hline$\lambda_{S M B}$ & $\begin{array}{c}2.00 \\
(128)\end{array}$ & $\begin{array}{c}2.77 \\
(119)\end{array}$ & $\begin{array}{c}-0.14 \\
(-0.08)\end{array}$ & $\begin{array}{c}0.42 \\
017)\end{array}$ & $\begin{array}{c}-0.72 \\
(-0.32)\end{array}$ \\
\hline$\lambda_{\text {HMLB }}$ & $\begin{array}{c}6.22 \\
(2.75)\end{array}$ & $\begin{array}{c}7.59 \\
(2.80)\end{array}$ & $\begin{array}{c}3.86 \\
(1.55)\end{array}$ & $\begin{array}{c}7.87 \\
(2.54)\end{array}$ & $\begin{array}{l}7.33 \\
(2.01)\end{array}$ \\
\hline$\lambda_{\text {WMLB }}$ & $\begin{array}{c}8.64 \\
(2.44)\end{array}$ & $\begin{array}{l}10.41 \\
(2.49)\end{array}$ & $\begin{array}{l}13.09 \\
(3.39)\end{array}$ & $\begin{array}{c}1.45 \\
(0.32)\end{array}$ & $\begin{array}{l}12.41 \\
(2.63)\end{array}$ \\
\hline$\lambda_{\text {LIQ }}$ & $\begin{array}{c}-2.30 \\
(-2.90)\end{array}$ & $\begin{array}{l}-1.64 \\
(-2.10)\end{array}$ & $\begin{array}{c}-2.61 \\
(-2.91)\end{array}$ & $\begin{array}{c}-0.22 \\
(-0.30)\end{array}$ & $\begin{array}{l}-2.57 \\
(-3.56)\end{array}$ \\
\hline $\bar{R}_{O L S}^{2}$ & 0.53 & 0.57 & 0.59 & 0.49 & 0.28 \\
\hline $\begin{array}{l}\text { MSPE } \\
\text { MAPE }\end{array}$ & $\begin{array}{l}0.38 \\
1.52\end{array}$ & $\begin{array}{l}0.41 \\
1.64\end{array}$ & $\begin{array}{l}0.55 \\
1.64\end{array}$ & $\begin{array}{l}0.17 \\
1.11\end{array}$ & $\begin{array}{l}1.25 \\
2.83\end{array}$ \\
\hline \multicolumn{6}{|c|}{ U.S. Funding Liquidity Measures } \\
\hline$\lambda_{M}$ & $\begin{array}{c}5.15 \\
(1.62)\end{array}$ & $\begin{array}{c}7.93 \\
(2.49)\end{array}$ & $\begin{array}{c}7.00 \\
(1.91)\end{array}$ & $\begin{array}{c}-1.37 \\
(-0.32)\end{array}$ & $\begin{array}{c}9.34 \\
(2.09)\end{array}$ \\
\hline$\lambda_{S M B}$ & $\begin{array}{c}2.03 \\
(1.28)\end{array}$ & $\begin{array}{c}3.06 \\
(1.31)\end{array}$ & $\begin{array}{c}-0.39 \\
(-0.23)\end{array}$ & $\begin{array}{c}0.42 \\
(0.17)\end{array}$ & $\begin{array}{l}-1.07 \\
(-0.47)\end{array}$ \\
\hline$\lambda_{\text {HMLB }}$ & $\begin{array}{c}4.67 \\
(2.02)\end{array}$ & $\begin{array}{c}7.19 \\
(2.70)\end{array}$ & $\begin{array}{c}4.50 \\
(1.81)\end{array}$ & $\begin{array}{c}7.87 \\
(2.53)\end{array}$ & $\begin{array}{c}7.93 \\
(2.25)\end{array}$ \\
\hline$\lambda_{\text {WMLB }}$ & $\begin{array}{c}8.40 \\
(2.32)\end{array}$ & $\begin{array}{l}10.31 \\
(2.46)\end{array}$ & $\begin{array}{l}13.17 \\
(3.45)\end{array}$ & $\begin{array}{c}1.46 \\
(0.33)\end{array}$ & $\begin{array}{l}12.34 \\
(2.68)\end{array}$ \\
\hline$\lambda_{\text {LIQ }}$ & $\begin{array}{c}-5.39 \\
(-4.07)\end{array}$ & $\begin{array}{l}-1.92 \\
(-1.91)\end{array}$ & $\begin{array}{c}-2.45 \\
(-2.43)\end{array}$ & $\begin{array}{c}-0.21 \\
(-0.17)\end{array}$ & $\begin{array}{c}-1.53 \\
(-1.89)\end{array}$ \\
\hline $\bar{R}_{O L S}^{2}$ & 0.61 & 0.57 & 0.56 & 0.48 & 0.18 \\
\hline $\begin{array}{l}\text { MSPE } \\
\text { MAPE }\end{array}$ & $\begin{array}{l}0.31 \\
1.43\end{array}$ & $\begin{array}{l}0.41 \\
1.61\end{array}$ & $\begin{array}{l}0.59 \\
1.73\end{array}$ & $\begin{array}{l}0.17 \\
1.12\end{array}$ & $\begin{array}{l}1.43 \\
2.93\end{array}$ \\
\hline
\end{tabular}


Table 15: Asset Pricing Tests with Funding Liquidity Risk and Small-Stock Factors Funding liquidity is proxied by the global or U.S. TED spreads. For further details see notes to Table 14. The sample period is November 1990 - July 2013.

\begin{tabular}{|c|c|c|c|c|c|}
\hline & Global & North America & Europe & Japan & Asia Pacific \\
\hline \multicolumn{6}{|c|}{ Global Funding Liquidity Measures } \\
\hline \multirow[t]{2}{*}{$\lambda_{M}$} & 5.42 & 8.67 & 6.89 & -1.27 & 9.99 \\
\hline & $(1.71)$ & $(2.71)$ & (1.88) & $(-0.30)$ & $(2.24)$ \\
\hline \multirow[t]{2}{*}{$\lambda_{S M B}$} & 2.04 & 2.86 & -0.06 & 0.34 & -1.55 \\
\hline & $(1.31)$ & $(1.22)$ & $(-0.04)$ & $(0.14)$ & $(-0.69)$ \\
\hline \multirow[t]{2}{*}{$\lambda_{\text {HмLS }}$} & 6.49 & 6.86 & 6.38 & 4.50 & 11.55 \\
\hline & $(3.22)$ & (2.19) & (2.95) & (1.93) & (4.48) \\
\hline \multirow{2}{*}{$\lambda_{\text {HMLB }}$} & 1.67 & 1.22 & 3.44 & 6.70 & 0.61 \\
\hline & $(0.85)$ & $(0.52)$ & (1.49) & $(2.28)$ & $(0.18)$ \\
\hline \multirow[t]{2}{*}{$\lambda_{\text {WMLS }}$} & 10.04 & 9.31 & 15.70 & 0.59 & 14.13 \\
\hline & (3.48) & $(2.48)$ & (5.50) & $(0.18)$ & (4.31) \\
\hline \multirow[t]{2}{*}{$\lambda_{\text {WMLB }}$} & 3.24 & 4.95 & 4.67 & 1.51 & 5.33 \\
\hline & $(0.97)$ & $(1.25)$ & $(1.28)$ & $(0.35)$ & (1.19) \\
\hline \multirow[t]{2}{*}{$\lambda_{\text {LIQ }}$} & 0.04 & -2.05 & -0.81 & -0.03 & -1.55 \\
\hline & $(0.05)$ & $(-2.58)$ & $(-1.13)$ & $(-0.05)$ & $(-2.13)$ \\
\hline $\bar{R}_{O L S}^{2}$ & 0.80 & 0.80 & 0.88 & 0.51 & 0.61 \\
\hline MSPE & 0.15 & 0.18 & 0.16 & 0.15 & 0.66 \\
\hline MAPE & 1.00 & 1.11 & 1.00 & 1.11 & 2.15 \\
\hline \multicolumn{6}{|c|}{ U.S. Funding Liquidity Measures } \\
\hline \multirow[t]{2}{*}{$\lambda_{M}$} & 5.36 & 8.56 & 6.88 & -1.26 & 10.31 \\
\hline & (1.68) & (2.69) & (1.88) & $(-0.30)$ & $(2.31)$ \\
\hline \multirow[t]{2}{*}{$\lambda_{S M B}$} & 2.05 & 3.18 & 0.03 & 0.34 & -1.83 \\
\hline & $(1.32)$ & (1.36) & $(0.02)$ & $(0.14)$ & $(-0.81)$ \\
\hline \multirow[t]{2}{*}{$\lambda_{\text {HMLS }}$} & 6.31 & 6.84 & 6.56 & 4.51 & 11.38 \\
\hline & (3.16) & (2.21) & (3.05) & (1.93) & $(4.44)$ \\
\hline \multirow[t]{2}{*}{$\lambda_{\text {HMLB }}$} & 1.86 & 0.81 & 2.68 & 6.65 & 0.34 \\
\hline & $(0.94)$ & $(0.35)$ & (1.17) & $(2.25)$ & $(0.10)$ \\
\hline \multirow[t]{2}{*}{$\lambda_{\text {WMLS }}$} & 10.09 & 9.64 & 15.85 & 0.56 & 13.87 \\
\hline & (3.49) & (2.58) & (5.56) & $(0.17)$ & (4.23) \\
\hline \multirow[t]{2}{*}{$\lambda_{\text {WMLB }}$} & 3.21 & 5.36 & 4.63 & 1.49 & 4.97 \\
\hline & $(0.96)$ & (1.36) & (1.26) & $(0.35)$ & (1.12) \\
\hline \multirow[t]{2}{*}{$\lambda_{\text {LIQ }}$} & -0.56 & -1.17 & 1.05 & 0.17 & -0.74 \\
\hline & $(-0.60)$ & $(-1.19)$ & (1.09) & $(0.15)$ & $(-0.85)$ \\
\hline $\bar{R}_{O L S}^{2}$ & 0.80 & 0.78 & 0.89 & 0.51 & 0.58 \\
\hline MSPE & 0.15 & 0.20 & 0.15 & 0.15 & 0.71 \\
\hline MAPE & 1.00 & 1.12 & 1.01 & 1.11 & 2.22 \\
\hline
\end{tabular}


(A) $\operatorname{adj} . R^{2}=-38.83 \%$

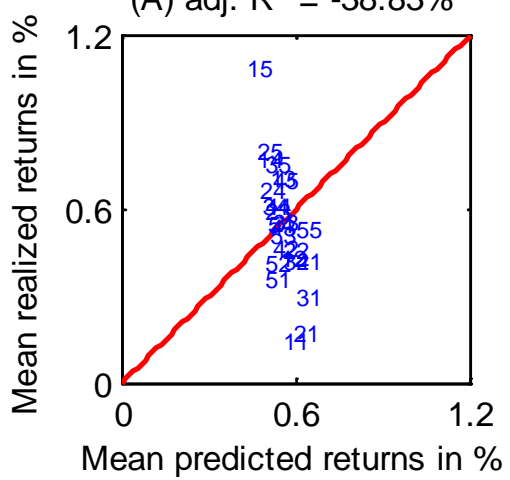

(C) $\operatorname{adj} . R^{2}=54.23 \%$

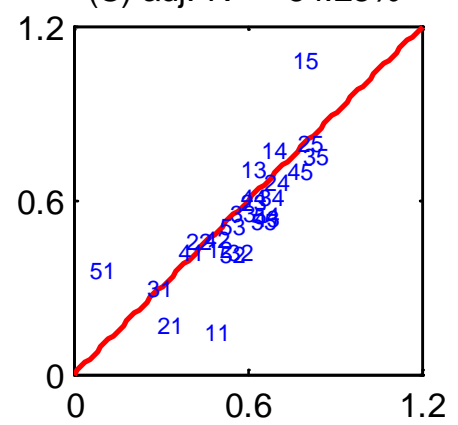

(B) $\operatorname{adj} . \mathrm{R}^{2}=45.23 \%$

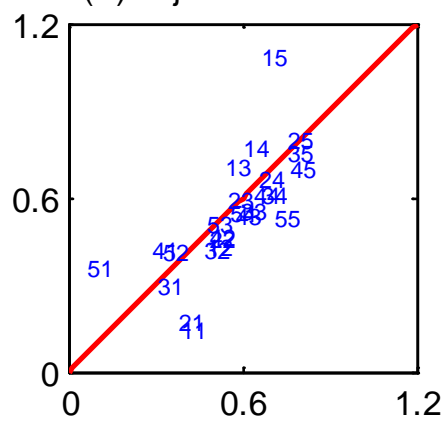

(D) $\operatorname{adj} . R^{2}=68.66 \%$

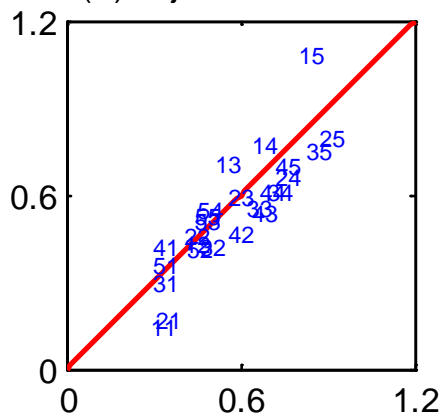

Figure 1: The Cross-Section of Global Value Portfolios

The four diagrams correspond (clockwise from top left) to (A) the CAPM, (B) threefactor Fama-French (1993) model, (C) four-factor Carhart (1997) model, and (D) modified Fama-French (1993) model with HML split into HMLS and HMLB. The horizontal axes correspond to the predicted average excess returns and the vertical axes to the sample average realized excess returns. The predicted values are from regressions presented in Table 5 . The test assets are 25 global portfolios formed on size and BE/ME. 

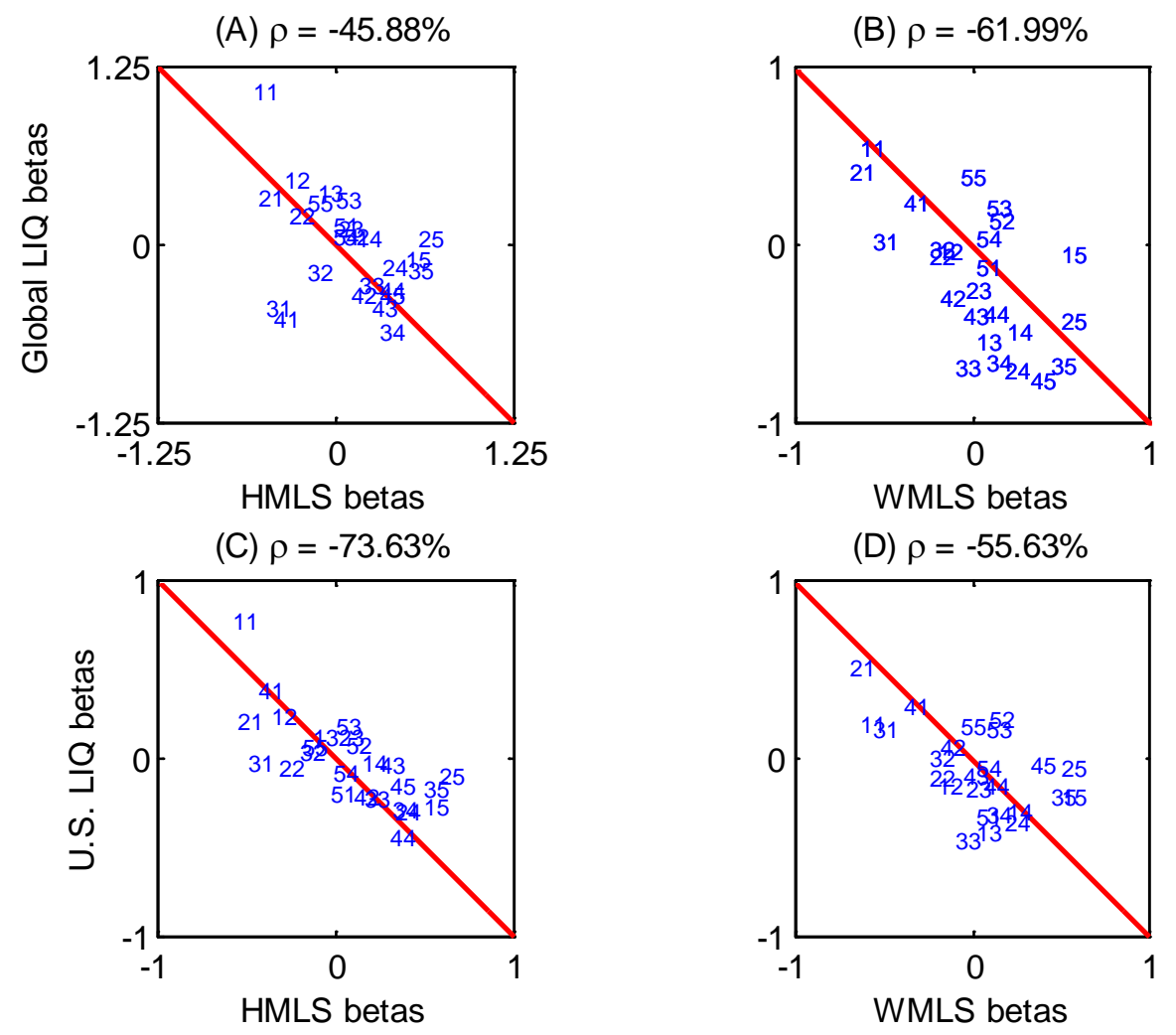

Figure 2: Risk Exposures of Global Value and Momentum Portfolios

The upper row plots global liquidity betas against the HMLS (WMLS) betas of global value (momentum) portfolios in (A), respectively, (B). These risk exposure estimates are presented in Tables 4 and 12. The bottom row plots U.S. liquidity betas against the HMLS (WMLS) betas of global value (momentum) portfolios in (C), respectively, (D). These risk exposure estimates are presented in Tables 4 and 13. 